\title{
Gastrointestinal Dysfunctions in Parkinson's Disease: Symptoms and Treatments
}

\author{
Andrée-Anne Poirier, ${ }^{1,2}$ Benoit Aubé, ${ }^{1}$ Mélissa Côté,,${ }^{1,3}$ Nicolas Morin, \\ Thérèse Di Paolo, ${ }^{1,2}$ and Denis Soulet ${ }^{1,2,3}$ \\ ${ }^{1}$ Axe Neurosciences, Centre de Recherche du CHU de Québec (Pavillon CHUL), Quebec City, QC, Canada \\ ${ }^{2}$ Faculty of Pharmacy, Laval University, Quebec City, QC, Canada \\ ${ }^{3}$ Department of Psychiatry and Neuroscience, Faculty of Medicine, Laval University, Quebec City, QC, Canada \\ ${ }^{4}$ Faculty of Medicine, Laval University, Quebec City, QC, Canada
}

Correspondence should be addressed to Denis Soulet; denis.soulet@crchul.ulaval.ca

Received 15 August 2016; Accepted 16 October 2016

Academic Editor: Shey-Lin Wu

Copyright (C) 2016 Andrée-Anne Poirier et al. This is an open access article distributed under the Creative Commons Attribution License, which permits unrestricted use, distribution, and reproduction in any medium, provided the original work is properly cited.

A diagnosis of Parkinson's disease is classically established after the manifestation of motor symptoms such as rigidity, bradykinesia, and tremor. However, a growing body of evidence supports the hypothesis that nonmotor symptoms, especially gastrointestinal dysfunctions, could be considered as early biomarkers since they are ubiquitously found among confirmed patients and occur much earlier than their motor manifestations. According to Braak's hypothesis, the disease is postulated to originate in the intestine and then spread to the brain via the vagus nerve, a phenomenon that would involve other neuronal types than the well-established dopaminergic population. It has therefore been proposed that peripheral nondopaminergic impairments might precede the alteration of dopaminergic neurons in the central nervous system and, ultimately, the emergence of motor symptoms. Considering the growing interest in the gut-brain axis in Parkinson's disease, this review aims at providing a comprehensive picture of the multiple gastrointestinal features of the disease, along with the therapeutic approaches used to reduce their burden. Moreover, we highlight the importance of gastrointestinal symptoms with respect to the patients' responses towards medical treatments and discuss the various possible adverse interactions that can potentially occur, which are still poorly understood.

\section{The Importance of Nonmotor Symptoms in Parkinson's Disease}

In the early 19th century (1817), with the publication of An Essay on the Shaking Palsy [1], Dr. James Parkinson was the first to provide a clear clinical description of the disease that now bears his name $[2,3]$. There are currently four motor features characterizing this neurological disorder, namely, muscle rigidity, tremor at rest, bradykinesia, and postural instability [3,4]. However, a definitive diagnosis of Parkinson's disease (PD) is difficult to establish and can be obtained only postmortem by the demonstration of the presence of Lewy bodies [3]. Therefore, clinicians currently rely not only on motor symptoms manifestations but also on a positive response to levodopa (L-DOPA) treatment [4].
Progressive alterations of dopaminergic (DAergic) neurons in the nigrostriatal pathway are at the core of the abovementioned motor symptoms, resulting in a dysfunction of the somatomotor system. The extent of dopamine (DA) loss in the substantia nigra is already about $50-70 \%$ when the first motor symptoms emerge, and although PD is a progressive neurological disorder, DAergic deterioration is usually very slow and varies from one person to another [4]. An early diagnosis of the disease based on the Unified Parkinson's Disease Rating Scale (UPDRS) has a favorable long-term impact on the quality of life of patients [3].

Over the course of PD progression, motor impairments are generally preceded by nonmotor symptoms (NMS) such as depression, olfactory deficit, sleep behavior disorder, and constipation, sometimes by up to ten years [5-8]. In his essay, 
James Parkinson had mentioned some of these nonmotor features, namely, constipation, sleep disorders, dysphagia, drooling (sialorrhea), bladder dysfunction, and a slight state of confusion [1]. Nowadays, NMS are increasingly associated with $\mathrm{PD}$, although they have not yet received extensive attention [6]. Indeed, patients report less than $40 \%$ of their nonmotor problems to healthcare professionals, either out of embarrassment or because these symptoms are seen as commonplace and inconsequential events [8]. To compound this problem, only a few NMS are recorded in medical files and are associated as such with PD, although those problems have been shown to result from the disease itself rather than being unremarkable manifestations of normal aging [9-12]. Therefore, these NMS, which are very often overlooked and are poorly investigated and treated, can have a major negative impact on the clinical care and quality of life of PD patients $[6,13-15]$. Patients also often indicate that their NMS are more difficult to manage than their motor problems and may sometimes result in their hospitalization and institutionalization $[6,15,16]$. In addition, it has been demonstrated that attenuating NMS greatly improves the quality of life of patients, particularly those who positively respond to a DAergic therapy $[15,17]$. Thus, the recently developed awareness on the detection of the different NMS early in the course of PD has led to a more critical appraisal of its etiology, the identification of risk factors, and the current advances in neuroprotective and therapeutic biomarkers of PD $[5,6,18-20]$. In light of these lines of evidence, PD can no longer be viewed solely as a complex disorder of motor functions, but rather as a progressive condition involving both motor and nonmotor features $[5,15,21]$. Some investigators have even proposed that PD could be divided into three phases, namely, preclinical, premotor (corresponding to the NMS), and motor phases $[6,20]$. In some patients, nonmotor problems can be reminiscent of complications resulting from pharmacological and surgical interventions for the treatment of motor symptoms [16]. NMS can also be more predominant in the "off" medication state and some might be alleviated by DAergic therapy or, on the contrary, be exacerbated by the latter [8]. Furthermore, the high costs associated with medical care and the aging population strongly stress the need to expand our knowledge base on all aspects of PD [13]. The various effects of which NMS are comprised and their highly divergent patterns of progression between PD patients further raise the challenge imposed by NMS in the management of PD [15].

About a decade ago, Dr. Braak et al. proposed the intriguing hypothesis that PD might result from an infection spreading first by intestinal and olfactory mucosae [22, 23]. This proposal followed the first description of Lewy bodies in the dorsal vagal nucleus by Friederick Lewy in the early 20 th century $[6,15]$. Based on Lewy bodies distribution in PD postmortem patients, Braak et al. also suggested six neuropathological stages, corresponding to disease evolution [23]. As such, the first signs of Lewy pathology appear in projection neurons of the dorsal motor nucleus of the vagus nerve at the early stage of $\mathrm{PD}$ [23]. Despite its potential interest, this hypothesis is not widely accepted, mainly because of the paucity of patients studied and the lack of associated clinical data [24]. However, the manifestation of NMS, preceding motor diagnosis, closely corresponds to the progression of Lewy pathology, supporting Braak's hypothesis [8]. Some studies have further suggested that the pathological process leading to PD could be initiated in the enteric nervous system (ENS) before spreading to the central nervous system (CNS) via autonomous connections such as through the vagus nerve $[25,26]$. In connection with the latter observation, a recent study has demonstrated that different forms of human alpha-synuclein ( $\alpha$-syn), the major protein component in Lewy bodies, injected in the intestine of mice can propagate to the brain via the vagus nerve and reach the dorsal motor nucleus in the brainstem, supporting Braak's hypothesis [27].

There are several different approaches to categorize the nonmotor features encountered in PD, but they have usually been separated into five major classes, namely, cognitive impairment, neuropsychiatric disorders, autonomic dysfunction, sleep disturbances, and other NMS [4-7]. Confusion and dementia are the most commonly reported cognitive impairments, whereas neuropsychiatric disorders rather occur as hallucinations, anxiety, depression, and impulse control disorders. Importantly, PD medication can potentially exacerbate some of the latter problems [13]. For example, the effects of DA agonists on the mesolimbic pathway could be responsible for impulse control disorders such as compulsive gambling, compulsive shopping, and hypersexuality [7, 28]. In addition, an injury to the autonomic nervous system can be observed in various peripheral NMS such as orthostatic hypotension, functional bladder disorder, excessive sweating, erectile dysfunction, and gastrointestinal (GI) symptoms such as constipation, drooling, dysphagia, and nausea [4, $6,13,16,26,28]$. Other nonmotor features that are still poorly categorized include pain, fatigue, unexplained weight changes, and visual as well as olfactory disturbances. To better identify these elements, Chaudhuri et al. developed the NonMotor Symptoms Scale, which allows for a more accurate measurement of the frequency and severity of NMS and allows determining the impact of treatment on these symptoms $[15,29]$. In addition, the Non-Motor Questionnaire, the Scales for Outcomes in Parkinson's Disease, and a revised version of the UPDRS (sponsored by the Movement Disorder Society) also contribute to the establishment of standardized and reliable means to assess NMS in PD $[8,30]$.

\section{GI Manifestations in Autonomic Disorders}

Early PD, when left untreated, is often accompanied by autonomic nervous system impairments among which GI symptoms represent the most common NMS [31]. Indeed, several studies relying on nonmotor rating scales have underscored the particular significance of GI symptoms in assessing the quality of life and have shown that these manifestations occur in $60 \%$ to $80 \%$ of patients $[13,16,32,33]$. GI disorders are among the most common causes of emergency admission and often result in severe complications such as malnutrition (15\% of PD patients), pulmonary aspiration $(2.4 \%$ of PD patients), megacolon (mostly asymptomatic; incidence 
unknown), intestinal obstruction (rarely reported; incidence unknown), and even intestinal perforation (a few cases reported; incidence unknown) [34-38]. Moreover, older age, DAergic medication, and higher disease severity are usually associated with these nonmotor features [28]. Hence, GI symptoms reflect disturbances of GI tract motility at all levels.

There are two major neural influences that regulate the GI tract, namely, the extrinsic pathway, which is associated with the vagus nerve, and the ENS, a component of the autonomic nervous system [39]. Due to its capacity to operate independently of the CNS and its 100 million neurons, the ENS is often considered as the second brain of the human body [39-41]. The ENS contains the myenteric and submucosal plexi, which are responsible for controlling smooth muscle activity in the GI tract [40, 41]. The latter intestinal function, which is regulated by the ENS, requires the involvement of several types of neurotransmitters such as DA, serotonin, acetylcholine, vasoactive intestinal peptide (VIP), substance $\mathrm{P}$, and nitric oxide synthase (NOS) [42]. Although the ENS has the ability to function independently of external stimuli, it also closely interacts with the vagal system $[39,41]$.

2.1. Constipation. Constipation is one of the initial NMS related to PD pathophysiology, affecting about $50-80 \%$ of patients. It often occurs early in the course of the disease and may precede the appearance of motor symptoms by several years $[6,13,28,31,43,44]$. Constipation is usually defined as fewer than three bowel movements per week and straining to pass stools [45]. Although constipation is mainly considered as a delay of the GI transit, some evidence suggests that it can also be ascribed to a paradoxical contraction of voluntary sphincters during defecation, resulting in difficulties with rectal expulsion. In the early stages of PD, decreased GI motility has been associated with neuronal loss in the myenteric and submucosal plexi and inclusions of Lewy bodies in the dorsal motor nucleus of the vagus, underscoring their potential role in slowing down intestinal peristalsis [7, 28, 32]. In addition to its association with autonomic alterations and, in some cases, urologic impairment, constipation is linked to a 2.7- to 4.5-fold increase in the risk of suffering from PD $[15,43,46]$. Constipation may also be accompanied by other GI features that can affect intestinal transit. For instance, pain, nausea, bloating, vomiting, and distension are all symptoms of paralytic ileus, inducing complete obstruction of the gut and affecting about $7 \%$ of parkinsonians. Anismus, the abnormal contraction of the external anal sphincter and puborectalis muscle during attempted defecation, is another problem that can occur in synergy with constipation in approximately $65 \%$ of $\mathrm{PD}$ patients, which is more frequently observed during "off” periods [16, 28, 47]. Other intestinal complications such as megacolon (mostly asymptomatic), pseudoobstruction, sigmoid volvulus, and bowel perforation may also arise in severe conditions, although their exact incidence is still currently unknown $[32,37,38,48]$.

2.2. Drooling. Also known as sialorrhea, drooling is the most common NMS of PD and is generally predominantly observed in the late stages of the disease and during the "off" state medication $[5,49,50]$. Affecting 70 to $80 \%$ of parkinsonians, sialorrhea corresponds to an exaggerated increase of saliva production and/or retention in the mouth cavity, with occasional overflow into the pharynx [13, 32, 49-51]. The submandibular, sublingual, and parotid glands are the three pairs of salivary glands responsible for most of the approximately 1.5 liters of saliva secreted daily and are controlled by the autonomic nervous system, mainly under parasympathetic cholinergic innervations $[52,53]$. Sialorrhea may result from three phenomena, namely, abnormal production of saliva, impairment of salivary clearance, and/or inability to maintain saliva in the mouth [51]. Furthermore, excessive salivary production may sometimes lead to serious complications, including saliva-induced asphyxiation and aspiration pneumonia [31, 45]. Different scales, such as Drooling Severity and Frequency Scales, Drooling Rating Scale, and Sialorrhea Clinical Scale for PD, have been proposed to assess sialorrhea according to standard criteria $[52,54,55]$. However, drooling is rarely due to overproduction of saliva but is rather more common due to dysphagia, which itself is essentially a manifestation of bradykinesia $[50,56]$. Indeed, in most PD patients, decreased salivary production is in fact observed $[51,56,57]$. Studies have shown that patients do not produce excessive amounts of saliva but rather have a more limited ability to swallow properly which, when associated with a forward head posture, might contribute to the onset of drooling $[32,49,58]$. In general, the inability to control oral secretions can affect eating and speech and cause social embarrassment [59]. Some patients even consider sialorrhea as their worst PD symptom [32]. Different factors can influence sialorrhea, such as male gender [60], aging [61], severity and duration of PD [62], hallucinations [59], orthostatic hypotension, dysphagia, dysarthria, UPDRS scores, and the use of antidepressants [51, 63]. Furthermore, the peripheral autonomic nervous system and the dorsal motor nucleus of the vagus nerve have been implicated in drooling, and Lewy bodies have been found in the submandibular salivary glands in some studies $[5,64]$.

2.3. Dysphagia. Dysphagia, a feature of PD pathophysiology, is defined as a difficulty in swallowing food, liquids, or pills due to an impaired function of the medullary center $[65,66]$. Dysphagia can result from muscular coordination dysfunctions in at least one of the three phases of deglutition: oral, pharyngeal, and oesophageal [67]. The main cause of swallowing difficulties, that is, a dysfunction of the oropharyngeal phase (found in about one-third of PD patients [68]), often results from motor symptoms of bradykinesia and a reduced motor control of the tongue. Thus, these motor features contribute to the pathophysiological development of dysphagia and, by extension, might also play a role in the onset of sialorrhea in PD [51]. Various abnormalities in the oropharyngeal phase, such as a delayed swallowing reflex, laryngeal movement deficits, and vallecular and piriform sinus residues, have been reported $[66,69]$. In the oesophageal phase, complete aperistalsis, simultaneous oesophageal spasms, slower oesophageal transit, and deficit in sphincter relaxation and pressure have been the predominantly observed abnormalities [67, 70]. 
Interestingly, this involuntary component of deglutition is under autonomic control, and Lewy bodies have been identified in the oesophageal myenteric plexus $[66,67]$. These findings suggest that swallowing impairment could partly result from direct damage to the ENS. Moreover, in view of the various aforementioned abnormalities, dysphagia is clearly linked to an increased risk of mortality by causing and/or exacerbating other PD-related complications such as aspiration pneumonia (estimated to account for $70 \%$ of the mortality rates among PD patients [36]), choking, malnutrition, unexplained weight loss, and dehydration $[13,66,69,71]$. Unfortunately, the degree of dysphagia cannot be predicted by $\mathrm{PD}$ progression because it has no direct connection with the clinical severity of the disease as evaluated by motor criteria [31, 70]. Moreover, data from various studies suggest that up to about $50 \%$ of parkinsonians might suffer from deglutition problems, which, as with drooling, occur mainly during the late stages of the disease $[66,71,72]$.

2.4. Nausea, Vomiting, and Gastroparesis. Nausea and vomiting (which are experienced by approximately $20 \%$ of patients [45]) are related, most of the time, to antiparkinsonian medications for motor symptoms, rather than occurring as intrinsic features of $\mathrm{PD}[6,7,28]$. Indeed, these side effects generally appear following the initiation of DAergic treatments [28]. However, nausea may likely occur in untreated parkinsonian patients as well, and such cases might be explained by underlying gastroparesis [73]. Also known as delayed gastric emptying, gastroparesis corresponds to decreased stomach motility, which may eventually affect gut transit. In addition to nausea, chronic gastroparesis is characterized by early satiety, a sensation of fullness, weight loss, and abdominal pain and bloating [74]. This phenomenon could well be related to the degeneration of autonomic neurons in the myenteric plexus and brainstem [45]. Moreover, intestinal absorption of L-DOPA and other medications might be slowed by such protracted gastric retention, thus reducing the effectiveness of treatment and preventing the improvement of motor symptoms [75]. PDassociated gastroparesis deserves proper medical attention as its observed prevalence approaches $90 \%$ of patients [76].

2.5. Pathophysiology. Recently, several clinical and postmortem studies exploring Lewy bodies expression and/or the presence of neurodegeneration in the enteric nervous system of parkinsonian patients have been conducted in order to better understand the etiopathogenesis of PD (see Table 1).

2.5.1. Lewy Bodies. The pathophysiological mechanisms underlying GI dysfunctions are likely to be multifaceted, reflecting not only the involvement of the intrinsic innervation of the gut, but also extrinsic inputs because of the presence of Lewy pathology in the dorsal motor nucleus of the vagus, sacral parasympathetic nuclei, and sympathetic ganglia [77-79]. The occurrence of Lewy pathology in the gut of PD patients was first reported in an autopsy survey in which Qualman et al. found myenteric Lewy bodies in the colon of one patient and in the esophagus of another [80].
A subsequent clinical study demonstrated the presence of Lewy bodies in the colon of one PD subject [81]. These primary observations led Wakabayashi et al. to perform a systematic assessment of Lewy pathology in the ENS of several PD patients [82]. Lewy bodies were found in the GI tract of seven patients and were distributed widely from the upper esophagus to the rectum. In a follow-up study, the same team reported that most Lewy bodies observed within the GI tract of the three patients were located in $\mathrm{VIP}^{+}$neurons and to a lesser extent in neurons immunoreactive for tyrosine hydroxylase (TH) [83]. Therefore, this suggests potential interplay between these neurons and cholinergic neurons of the vagus nerve contributing to the spread of $\alpha$-syn to the CNS. It was also mentioned that few Lewy bodies were found in neurons that were negative for either VIP or TH. To date, these have been the only studies suggesting that a specific subset of enteric neurons could bear Lewy pathology [83]. No further reports regarding GI Lewy pathology in patients with PD were published, until 2006 when Braak et al. brought this topic to the forefront [84]. In this postmortem study, they investigated the gastric myenteric and submucosal plexi from five individuals with Lewy body disease. Clinical data demonstrated that three out of the five patients with Lewy body pathology displayed motor symptoms reminiscent of PD while the other two patients were reported to be free of such symptoms. However, Lewy pathology was present in both the myenteric and the submucosal plexi of all five patients. This led Braak and colleagues to postulate that the pathology initiates in the ENS before progressing to the CNS [84]. Despite being a potentially important finding, this hypothesis has not been widely accepted, mainly because of the paucity of patients studied and the lack of associated clinical data [24]. More recently, a comprehensive survey on the occurrence of Lewy pathology in the peripheral nervous system, and especially in the ENS, has been published by the Arizona Parkinson's Disease Consortium [79]. One of the most striking results of this study was the identification of Lewy inclusions in the esophagus of 14 out of $15 \mathrm{PD}$ patients, suggesting that enteric pathology is present in the vast majority of $\mathrm{PD}$ cases [79]. Other recent studies have also observed $\alpha$-syn positive staining in GI tissues collected before patient's diagnosis [85] and in the vast majority of parkinsonian patients' colon tissues [86, 87].

The abovementioned data on the ENS in PD patients were collected either at autopsy or using colectomy specimens. To extend this work by analyzing enteric neuropathology in living patients, Lebouvier et al. took advantage of a novel colonic biopsy technique $[88,89]$. Twenty-nine patients with an established PD diagnosis were enrolled together with 10 healthy subjects who had undergone colonoscopy for colorectal cancer screening. Biopsies from 21 out of the 29 patients with PD (72\%) showed Lewy neurites in their submucosal plexus, whereas no Lewy pathology was observed in any of the controls [89]. Chronic constipation was more frequent in patients with than without Lewy neurites, suggesting a pathogenic role for these inclusions. However, Lebouvier et al. did not consider the myenteric plexus, which is directly involved in the control of bowel motility [89]. These findings are in line with other reports 


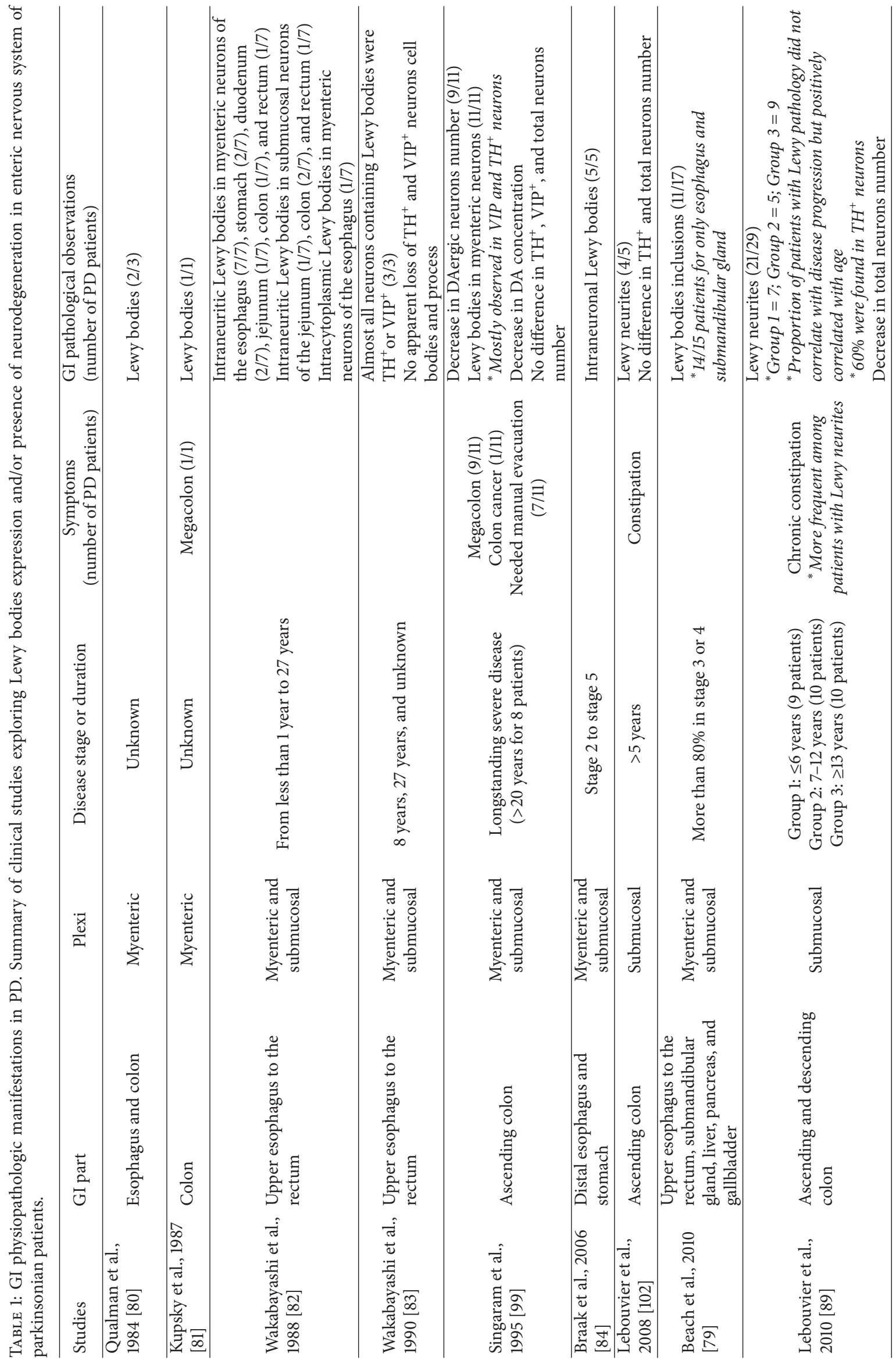




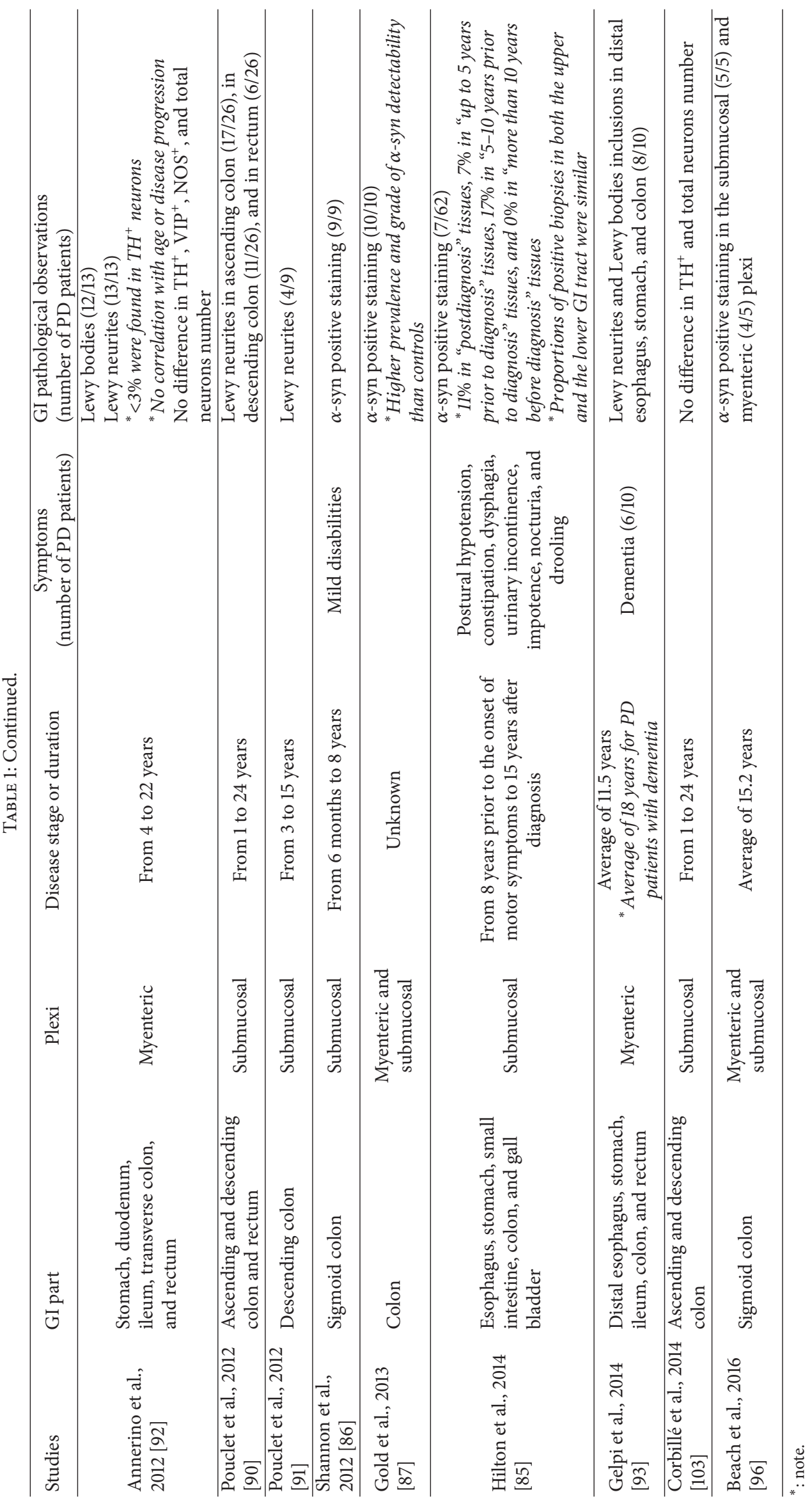


on PD enteric pathology, which showed that, besides Lewy bodies, Lewy neurites were also observed in the ENS of patients [79, 84, 90-93]. Using $\alpha$-syn immunostaining, the authors also demonstrated that approximately half of the Lewy neurites observed in the submucosal plexus belonged to postganglionic neurons, thus supporting their extrinsic origin [84]. The origin of the remaining Lewy neurites remains to be determined, but it is possible that they could originate both from submucosal and from myenteric neurons, which have been shown to project to the submucosal blood vessels [94]. This observation is in agreement with recent studies showing $\alpha$-syn immunolabeling in the submucosal perivascular regions $[95,96]$. Depending on the type of $\alpha$-syn immunostained and the intestinal region studied, some discrepancies in the observation of Lewy bodies in GI biopsies or postmortem tissues are possible, especially because $\alpha$-syn is physiologically expressed by red blood cells and vascular endothelial cells [96].

Interestingly, an animal model of PD recently developed provides some clues on the role of ENS alterations in GI dysfunction. Transgenic $\alpha$-syn SNCA, A53T, and A30P mice display aggregates within their enteric ganglia, which is associated with a prolonged whole-gut total transit time and reduced colonic motility [97]. However, there is no evidence of pathologic changes in the dorsal motor nucleus of the vagus or autonomic cardiovascular dysfunction. These findings suggest that ENS alterations in these mice are intrinsic in origin, being caused by $\alpha$-syn aggregation in enteric neurons only. It is possible in PD patients that at least some of the GI symptoms could be caused by enteric neuropathy. It should be pointed out, however, that studies on GI symptoms in PD have focused mainly on motility disorders and therefore the role of the myenteric plexus and associated consequences of Lewy pathology in the submucosal plexus have, to our knowledge, not been addressed either in patients or in experimental models of PD.

2.5.2. Neurodegeneration. Enteric neurons produce a substantial amount of DA which regulates normal gut motility [67]. Interestingly, slowed GI transit and decreased gut contraction in PD patients occur via altered DA-ENS circuitry, which normally promotes the peristaltic reflex [98]. PD patients with severe constipation have been reported to present lower levels of GI DA, suggesting that damage to the enteric DAergic system might be an important factor underlying GI dysfunction [99]. More recently, age-related loss of myenteric neurons has been associated with chronic constipation, although studies are widely controversial [100, 101]. Unfortunately, it is still not clear whether PD leads to the loss of enteric neurons. Singaram et al. reported that most patients present DAergic neuronal loss in the colonic myenteric and submucosal plexi, whereas other types of neurons were not affected based on TH immunostaining [99]. Other teams also used this marker on postmortem tissues and colon biopsies, and none reported DAergic enteric neuronal loss $[88,92,102,103]$.

Systemic administration of the selective DAergic neuronal toxin 1-methyl 4-phenyl 1,2,3,6-tetrahydropyridine
(MPTP) leads to the loss of DAergic neurons in the intestinal tracts of mice [104, 105], but MPTP-treated monkeys were reported to display an increased number of neurons in their myenteric ganglia [106]. MPTP causes a transient increase of stool frequency and colon relaxation lesions in mice [104], although this effect is inconsistent with the slow GI motility of PD patients. Therefore, despite the fact that inhibitory intestinal DAergic neurons could be impaired in PD, these neurons are not the only neuropathological targets of the disease [106-108]. Indeed, intestinal non-DAergic neurons could also be impaired, but the discrepancy between data makes it difficult to draw robust conclusions. Anderson et al. demonstrated that MPTP-treated mice presented no difference in nitric oxidergic neurons [104]. Another study showed in a PD model induced by directional stereotaxic brain injection of the neurotoxin 6-hydroxydopamine (6OHDA) that rats exhibited slow colon motility accompanied with nitric oxidergic neuron loss in the myenteric plexus [109]. Other studies showed that a primate MPTP model led to an increase in nitric oxidergic neurons [106]. Overall, most of these studies have shown that GI cholinergic transmitters were not significantly altered in PD $[104,106,110]$.

According to these data, constipation in PD patients cannot be explained solely by a decrease in DA levels linked to damage to neurons. Digestive tract motility would require sophisticated synchronization from all neurotransmitters, not only DA. Moreover, the important variability between the results pertaining to enteric neuronal loss refers to the neurodegenerative paradox. Even if DAergic neuronal death is the histopathological hallmark of PD, it is one of the most difficult parameters to highlight in the ENS because of both the rarity of apoptosis in the neurodegenerative process and the difficulty in counting neurons [111]. This has together led to numerous unanswered questions concerning neurodegenerative processes occurring in the ENS and their impact on GI impairments.

2.6. Other Outcomes of PD Therapies on GI Dysfunctions. Antiparkinsonian medication considerably hampers the evaluation of the potential correlation between GI dysfunctions and the severity of PD symptoms. An individual stabilized by drug therapy may indeed display a better overall condition than another patient with early $\mathrm{PD}$, thus receiving a suboptimal treatment [37]. Moreover, in some situations, addressing motor symptoms only may affect GI features both positively and negatively. Indeed, DAergic therapy may improve dysphagia and drooling but, on the other hand, might also worsen gastroparesis and reduce GI motility $[69,75,112]$. However, since nausea and vomiting are often side effects of various medications, they can limit the use of the latter and, as a result, preempt the benefit of such medications on motors symptoms [31]. Moreover, deep brain stimulation (DBS), which is widely used to treat motor symptoms, has been shown to have a potential impact on the manifestation of GI symptoms [113, 114]. According to some studies, constipation and deglutition are significantly improved after surgery in the subthalamic nucleus [115-117]. However, there is no consensus on the putative effect of DBS 


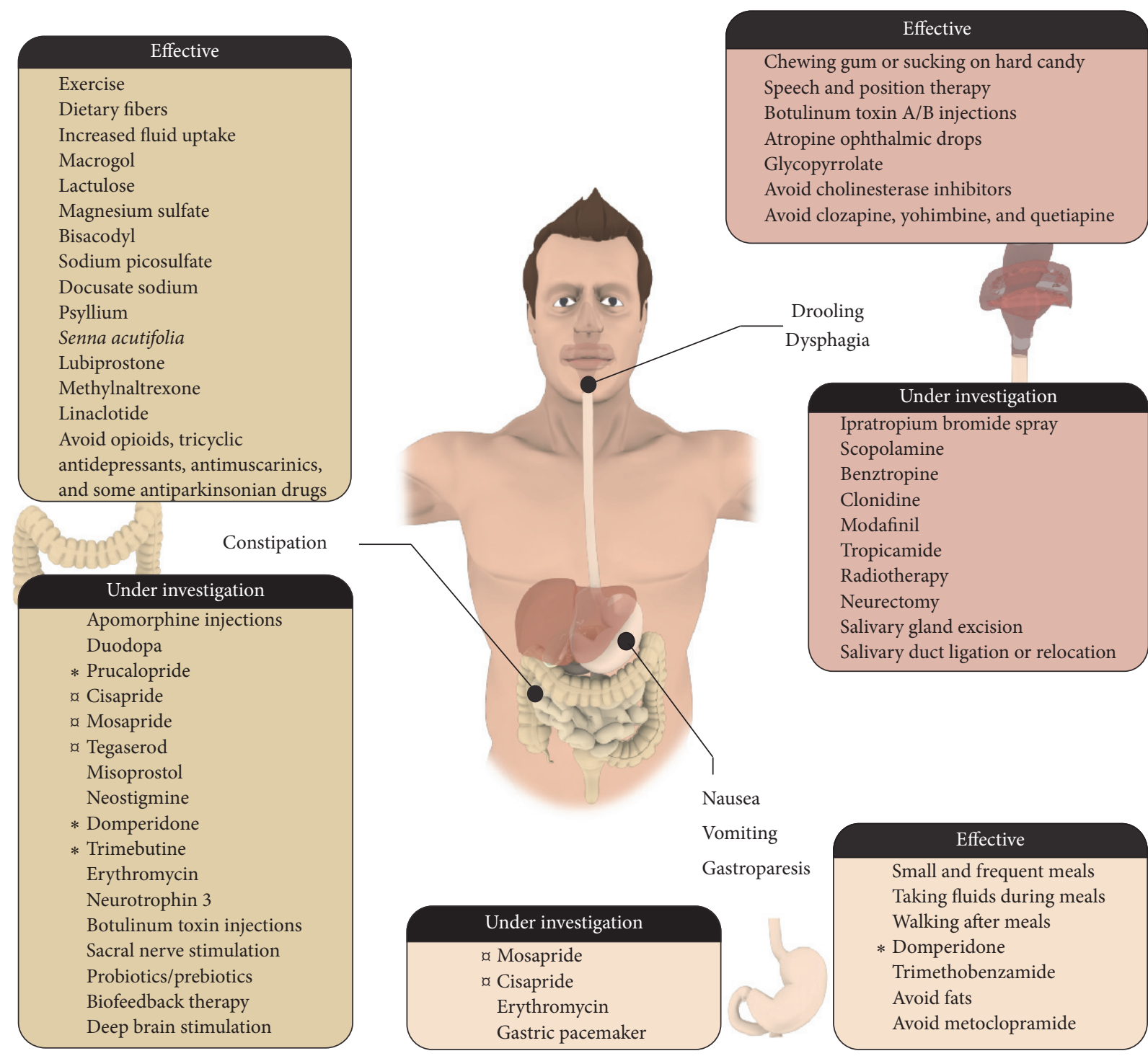

* Not available in the United States

a Withdrawn from the market

FIGURE 1: Treatment options for gastrointestinal dysfunctions in Parkinson's disease. Overview of the different pharmacological treatments or therapeutic approaches that are currently effective or under investigation to manage constipation (left panels), drooling/dysphagia (right panels), and nausea/vomiting/gastroparesis (bottom panels). Please note that some drug options are not available in the USA (*) or had to be withdrawn from the market due to unacceptable side effects $(\not)$.

on GI manifestations, as shown by reports that the latter neurosurgery does not improve dysphagia and drooling [51, $118,119]$.

\section{Therapeutic Approaches to GI Symptoms}

Importantly, GI impairments can impact other symptoms, which further complicates the clinical management of PD. For instance, GI problems such as gastroparesis and delayed intestinal absorption might lead to more erratic absorption of L-DOPA, which is reflected by motor fluctuations [120]. The latter problem emphasizes the necessity for clinicians to exert due vigilance during office visits of PD patients and regularly ask specific questions regarding GI manifestations. Recent studies have also provided evidence for symptomatic treatments of constipation and drooling, but, unfortunately, the current armamentarium for dysphagia and nausea remains quite limited [31]. In this regard, Figure 1 and Table 2 provide a summary of GI symptoms as well as the current treatment alternatives.

\subsection{Constipation}

3.1.1. Effective Treatments. To prevent constipation problems in $\mathrm{PD}$, therapies aimed at accelerating colonic transit may be 


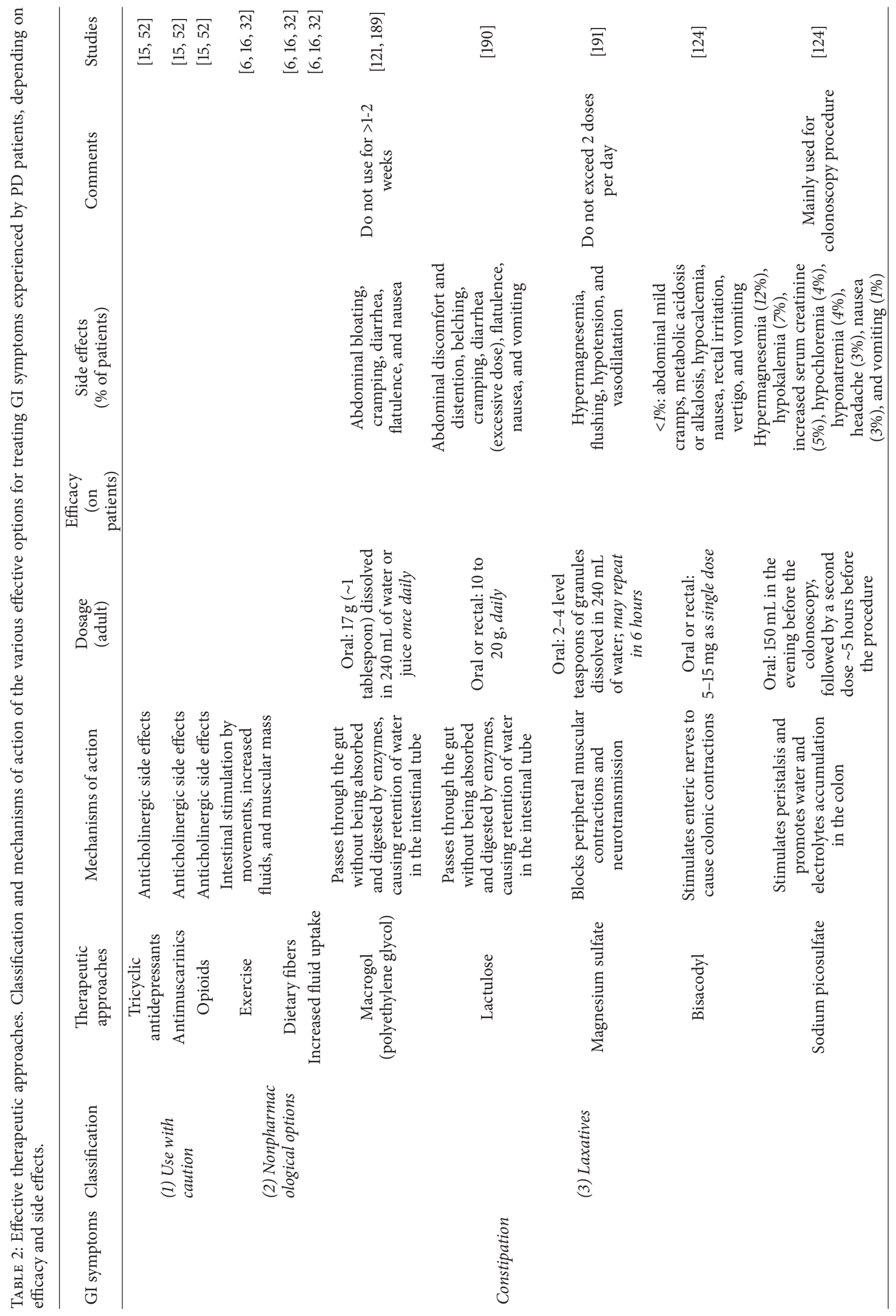




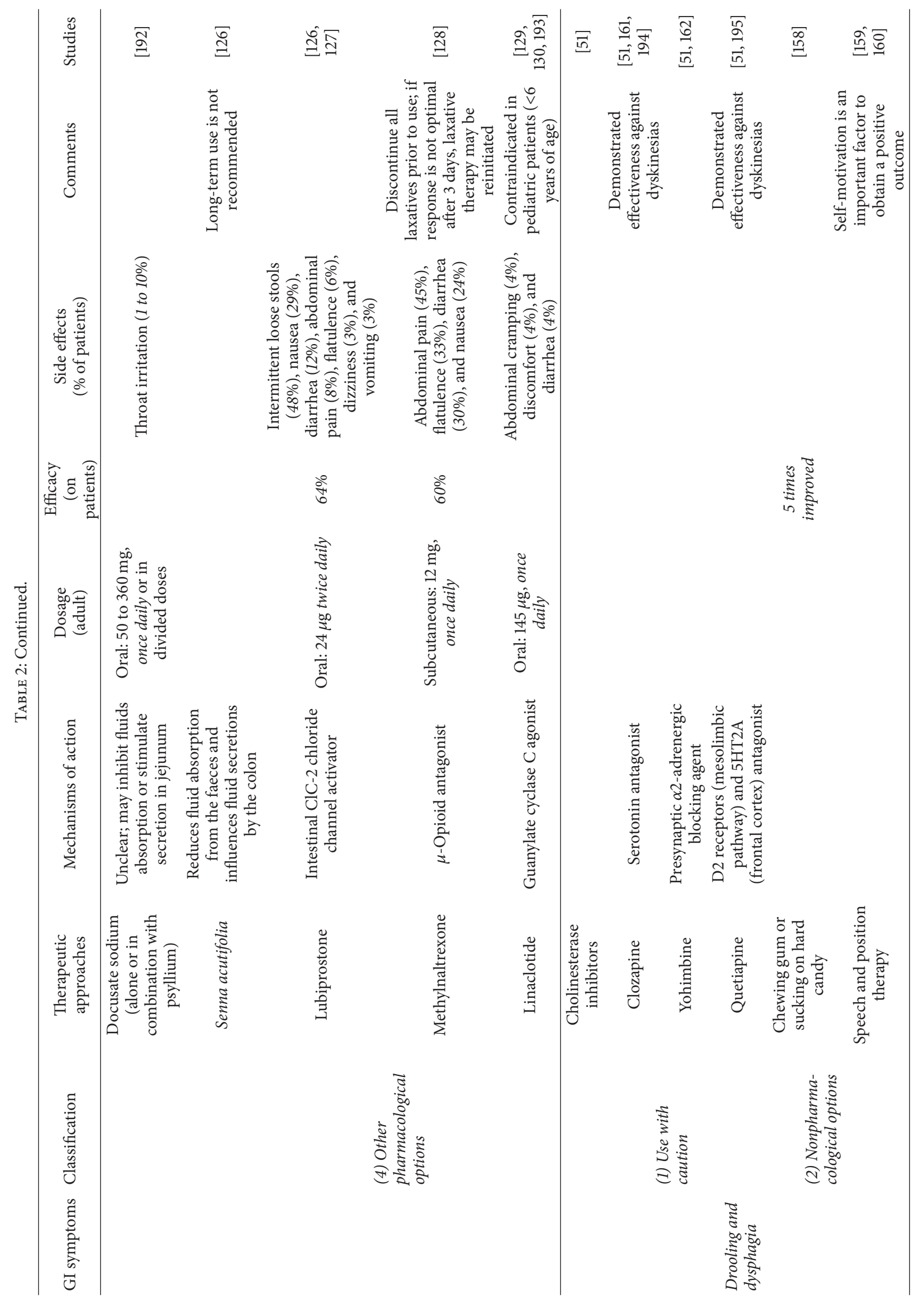




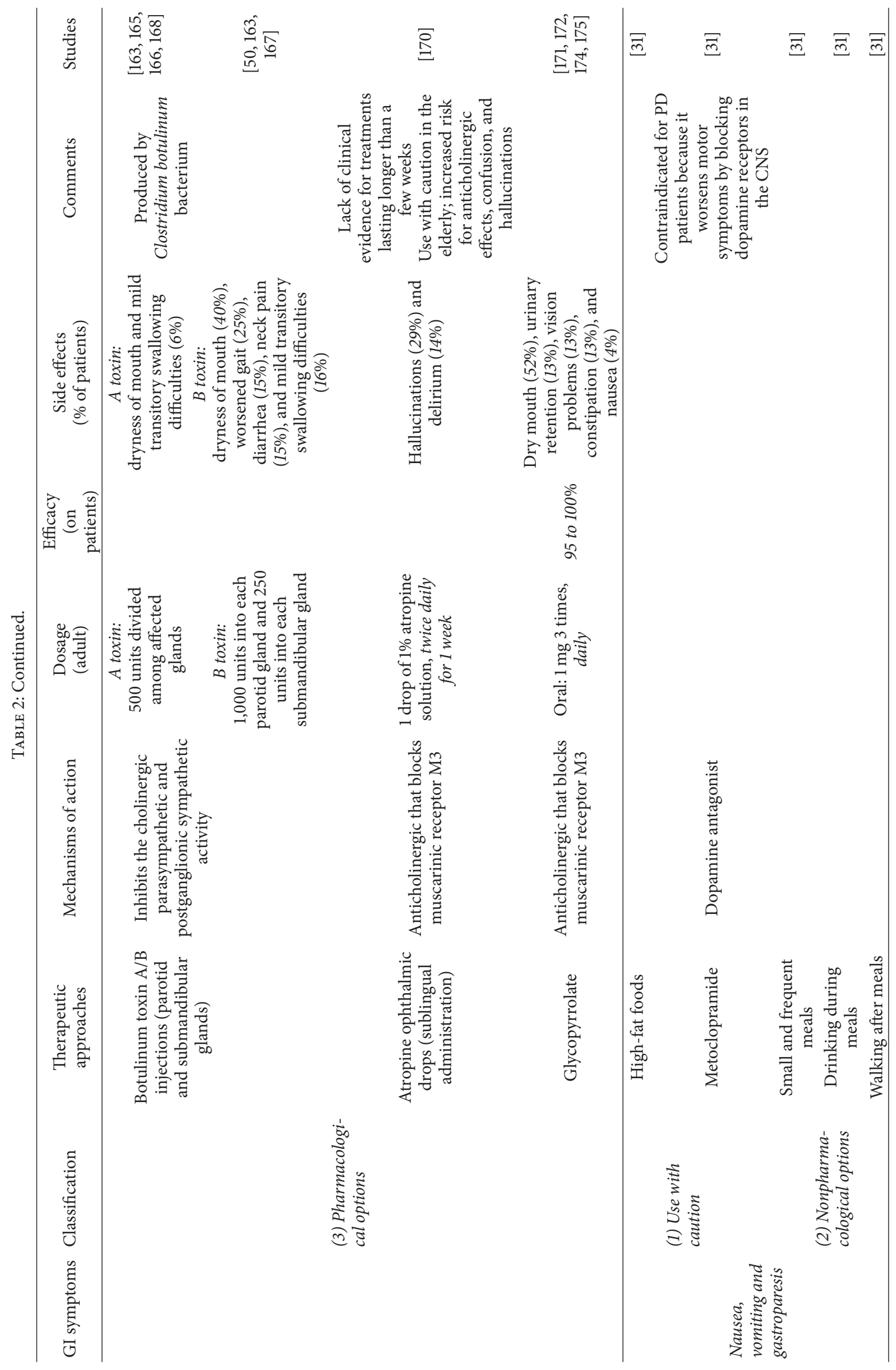




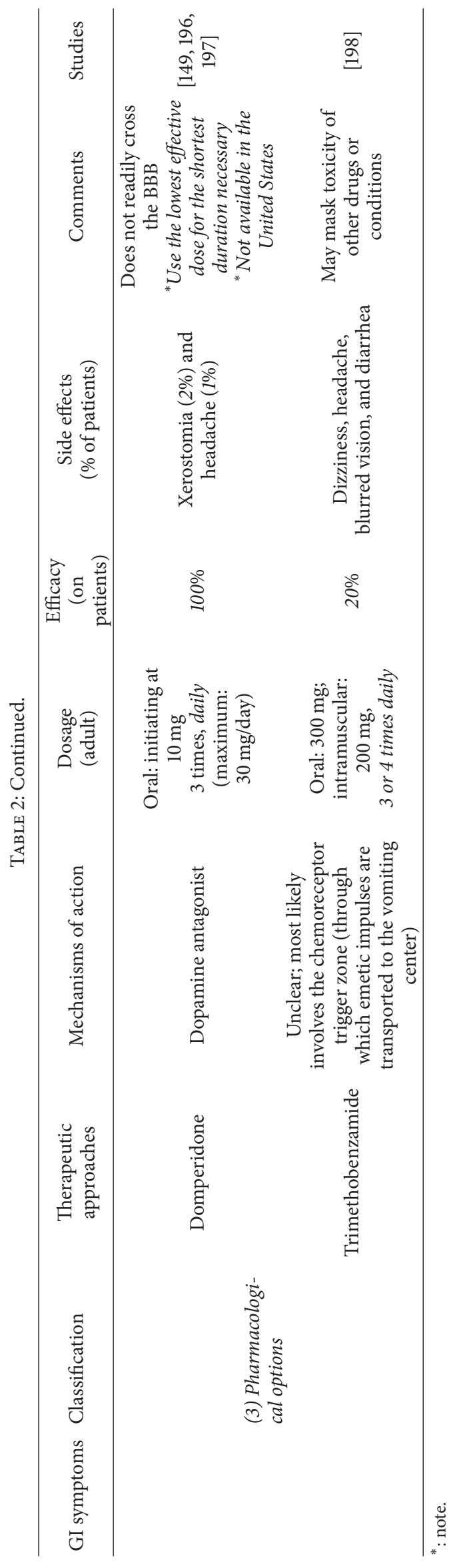


effective. Increasing the levels of daily activity and introducing dietary changes are the first options to consider. Patients should be encouraged to maximize dietary fibers (cereals, bran, citrus fruits, etc.), as well as ensure adequate fluid intake to avoid dehydration $[6,15,16,32]$. Nevertheless, an exhaustive pharmaceutical evaluation of the drug treatments already prescribed to patients is important before introducing additional measures. Indeed, the dosage of medications known to increase constipation symptoms should be optimized as much as possible. Some antiparkinsonian drugs as well as opioids, tricyclic antidepressants, and antimuscarinics are recurrent sources of severe constipation, likely due to their anticholinergic effects $[15,52]$. Other available options to increase the frequency of bowel movements and improve stool consistency are (i) osmotic laxatives such as macrogol (polyethylene glycol), lactulose, and magnesium sulfate, (ii) stimulant laxatives such as bisacodyl and sodium picosulfate, and (iii) stool softeners [28, 30, 121-123]. The safety profile associated with the long-term use of osmotic agents makes them the preferred group of laxatives. Macrogol, which is available in the USA and is recommended by the American Academy of Neurology and the Movement Disorders Society, is considered to be an effective and safe osmotic laxative for PD patients [15, 32, 121]. Bisacodyl and sodium picosulfate, which both act by stimulating colonic smooth muscle contractions as well as electrolyte and water secretion, may represent additional alternatives to treat constipation [124]. Moreover, stool softeners such as docusate sodium may be used alone or in combination with psyllium husks to increase stool volume and, therefore, peristalsis reflex $[6$, $7,125]$. By increasing intestinal fluid secretion, lubiprostone, an intestinal ClC-2 chloride channel activator, also improves constipation issues ( $64 \%$ of PD patients) [7, 28, 52, 126]. The most common adverse events observed were intermittent loose stools ( $48 \%$ of PD patients), nausea (29\%), diarrhea (12\%), abdominal pain (8\%), flatulence (6\%), dizziness (3\%), and vomiting (3\%) [52, 126, 127]. Methylnaltrexone $(\mu$ opioid antagonist) is another medicinal agent approved in the USA and indicated for the treatment of opioid-induced constipation, with approximately $60 \%$ of patients having reported beneficial intestinal effects $[28,128]$. In 2008, a clinical trial led by Portenoy et al. showed that adverse effects experienced by patients taking methylnaltrexone are mostly abdominal pain (45\%), flatulence (33\%), diarrhea (30\%), and nausea (24\%) [128]. Linaclotide, a guanylate cyclase C agonist, has also recently been approved by the Food and Drug Administration (FDA) as a treatment for irritable bowel syndrome and chronic constipation. Abdominal cramping, discomfort, and diarrhea are the adverse events commonly reported by patients for linaclotide (about 4\%) $[52,129,130]$. Finally, several other studies have also demonstrated the effectiveness of the Senna acutifolia plant, but the long-term use of this well-known laxative is not recommended [122].

3.1.2. Treatments under Investigation. Treating constipation remains an active research area and various studies have assessed the impact and clinical relevance of options that could help relieve the discomfort and adverse effects associated with this GI problem encountered in PD. For example, subcutaneous injections of apomorphine have translated to positive effects on intestinal motility (improvement of the defecatory mechanisms and anorectal dysfunction [6, 32, $131,132]$ ) and UPDRS motor scores (in about $70 \%$ of PD patients [133]), although adverse effects such as orthostatic hypotension (in $50 \%$ of patients), nausea, and drowsiness (in $75 \%$ of patients) may occur following administration of this DA agonist $[8,134]$. It is also recommended that patients use an antiemetic as a pretreatment before receiving injections in order to avoid the unpleasant effect of nausea [31]. Therefore, due to these various secondary effects, the long-term use of apomorphine appears to be inadvisable [32] . Intrajejunal infusion of L-DOPA/carbidopa (or duodopa) has also proved beneficial relatively to constipation problems (in approximately $70 \%$ of $\mathrm{PD}$ patients) $[135,136]$. Moreover, a body of research has been heavily focused on different ligands (agonists or antagonists) of the $5-\mathrm{HT}_{4}$ serotonin receptors. These receptors, which are located partly in the smooth musculature and cholinergic nerves of the GI tract, are, among others, capable of increasing gastric and colonic motility by facilitating acetylcholine release [137-139], thus making them an attractive target for treating constipation. The main $5-\mathrm{HT}_{4}$ agonists studied to date are prucalopride, cisapride, mosapride, and tegaserod [137, 140-142]. Unfortunately, although these agonists were found to be effective in the treatment of constipation in PD patients, those prokinetic agents have been removed from the US market or have not been approved by the FDA due to possible adverse cardiovascular effects (less than 1\% of patients) [141, 143-145]. Other medicinal agents are also under investigation, such as misoprostol (a prostaglandin $\mathrm{E}_{1}$ analogue; 55\% efficacy) $[32,146]$, neostigmine (an acetylcholinesterase inhibitor; $50 \%$ efficacy) [7, 147], and domperidone (a DA antagonist; about 35\% efficacy) [148]. However, even if the promotility agent domperidone could be potentially effective, due to its absence of permeation through the blood-brain barrier (BBB) [149], there is insufficient evidence to recommend its utilization for constipation, as in the case of trimebutine (an enkephalinergic agonist) and erythromycin (the well-known macrolide antibiotic) [143]. In recent years, the NGF receptor agonist neurotrophin 3 has also been studied to improve GI motility dysfunction in PD. Although its mechanism of action with respect to GI motility remains unknown, this neurotrophic factor was found to be effective in treating constipation (in about $20 \%$ of patients) $[52,150]$. In a clinical trial conducted by Pfeiffer et al., a reduced colonic transit time, an increase in stool frequency, and shortening of the intervals without stool were observed [151]. However, abdominal cramps and diarrhea were noted in three patients, who were forced to reduce neurotrophin 3 dosage $(300 \mu \mathrm{g} / \mathrm{kg}$ three times weekly) [151]. Injections of botulinum toxin (BTX), a neurotoxin produced by the Clostridium botulinum bacterium that inhibits acetylcholine release, have also been proposed to help reduce constipation burden in PD [51, 152]. However, not only are such injections technically challenging, including ultrasound guidance, but also there is insufficient evidence that this method offers an effective treatment [30, 
153, 154]. For example, Albanese et al. reported a beneficial clinical effect of BTX injections on constipation, but only in a single patient [153]. In another clinical study, Cadeddu et al. observed an improvement of constipation symptoms in 10 out of 18 patients after two months of BTX treatment [154]. However, the authors mentioned that repeated injections could be necessary to maintain this clinical improvement since the effects of the toxin wear off within three months of administration. Nonpharmacological strategies have also been put forward to treat constipation, such as sacral nerve stimulation (with 57\% efficacy) [28, 155], synbiotic yogurt (i.e., probiotic- and prebiotic-enriched yogurt) [7, 16, 52], biofeedback therapy (79\% efficacy) [52], and DBS (about $25 \%$ efficacy after two years of treatment, a percentage that might however be influenced by the postoperative reduction in DAergic therapy and an improvement in motor fluctuations) [116, 117]. Milk fermented with the probiotic strain Lactobacillus casei Shirota has also been suggested to dampen constipation problems by modulating the host immune response, enhancing mucosal function, suppressing growth of pathogenic bacteria, and blocking epithelial attachment by pathogens, resulting in an improvement in 70 constipated adults $[156,157]$. A decrease in abdominal pain, bloating, and sensation of incomplete emptying is also observed in patients using probiotics [52].

\subsection{Drooling and Dysphagia}

3.2.1. Effective Treatments. For patients with mild symptoms of drooling and/or dysphagia, chewing gum or sucking on hard candy may be effective in ameliorating swallowing (an approximately 5-fold improvement) and thus reduce drooling $[13,67,152,158]$. Speech and position therapies can also prove efficient for easing these GI symptoms (with 60 to $90 \%$ efficacy) [159]. These therapies consist basically in training to learn voluntary airway protection techniques through adequate swallowing methods and improved head postures. Marks et al. investigated such techniques and observed that self-motivation was an important factor in obtaining a positive outcome [160]. It is strongly recommended to consider all these nonpharmacological options first to improve drooling and dysphagia symptoms before changing over to drugbased solutions. However, such drug-free approaches may only provide temporary improvement and might not be effective or suitable for all patients. Indeed, pharmacological treatments are generally considered when more aggressive intervention is required [31]. It must be emphasized that some categories of medications used to treat other PD symptoms may in fact aggravate drooling and dysphagia and should thus be avoided as much as possible. Such medications include acetylcholinesterase inhibitors, the antipsychotic quetiapine, and adrenergic receptor agonists such as clozapine and yohimbine [51, 161, 162]. The pharmacological treatment most often mentioned for drooling/dysphasia is undoubtedly BTX injections. Local injections of this toxin in the parotid and submandibular glands inhibit the cholinergic parasympathetic and postganglionic sympathetic activity, thereby reducing saliva production [163]. This treatment, which denervates the salivary glands, was shown to be effective in reducing drooling severity and frequency (in about 80 to $90 \%$ of patients) without compromising swallowing [50, 51, 164-167]. Unfortunately, published studies cannot be easily compared due to the important disparity between the methodologies employed. Indeed, there is no standard technique for the injection (gland, ultrasound guidance, etc.) and no compliance regarding the optimal dose to be administered [51]. The sole guideline for achieving the best effect using this therapeutic approach is to inject the toxin bilaterally and periodically $[31,163]$. Dryness of the mouth (or xerostomia) is the common adverse effect observed with BTX [51]. Importantly, submandibular glands injections are recommended only under the supervision of a specialist due to potential side effects caused by spreading of the toxin to nearby structures and should be performed exclusively when treatment of the parotid gland alone is insufficient [163]. Among the several serotypes of BTX, only A and B have been studied and are commercially available [51]. In the majority of these studies, no side effects were observed with BTX-A, although BTX-B injections induced mild adverse events such as dry mouth (in about $40 \%$ of patients), diarrhea $(\sim 15 \%)$, neck pain $(\sim 15 \%)$, and worsened gait $(\sim 25 \%)[50,168,169]$. This suggests a preferential action of BTX-B on autonomic neurons and therefore might point to its higher effectiveness compared to BTX-A [152]. However, in two different clinical trials, Lagalla et al. observed that some patients experienced mild transitory swallowing difficulties 7 days after a BTX-A injection (in about $6 \%$ of patients) [166] and 10 days after a BTX-B injection ( 16\%) [167], but they recovered within 10 to 14 days. In spite of these potential drawbacks, these studies, which are the only ones that have compared the A and B serotypes, failed to demonstrate a significant difference in the effectiveness between both neurotoxins [166, 167]. Other pharmacological alternatives to BTX in the treatment of drooling/dysphagia include anticholinergic drugs that block muscarinic receptors and particularly the M3 subtype. Nevertheless, the currently available agents are not selective for M3 receptors and might thus give rise to several undesirable side effects (e.g., confusion, hallucinations, drowsiness, urinary retention, and constipation) [51]. Thus, some of these drugs have yet to be considered truly effective, which warrant further investigations. A few studies have claimed that the two anticholinergics, atropine and glycopyrrolate, are the only potentially useful therapies available for improving drooling/dysphagia [51, 52, 123]. Despite being effective, atropine still causes a wide range of undesirable adverse effects such as hallucinations (2/7 patients) and delirium (1/7 patients; but this was confounded by a concomitant urinary tract infection) [170]. Since glycopyrrolate does not cross the $\mathrm{BBB}$, unlike atropine, it is therefore the preferred agent because it is less likely to cause adverse effects in the CNS [152, 171]. Between 95 and $100 \%$ of patients who completed clinical studies reported improvement in drooling/dysphagia with glycopyrrolate [172-174]. As expected, the side effects observed occurred in the periphery and mostly included xerostomia (in approximately $52 \%$ of patients), urinary retention (13\%), constipation (13\%), vision problems (13\%), and 
nausea $(\sim 4 \%)[171,175]$. While anticholinergics might be efficient for treating drooling/dysphagia, they do not represent a suitable option for PD patients since other NMS can be subsequently worsened. Moreover, there is a lack of clinical evidence for treatments lasting longer than a few weeks and the long-term adverse effects of atropine and glycopyrrolate have not been documented, thus leaving important safety issues unresolved [51, 171]. All the pharmacological options listed above may thus be regarded as effective treatments for drooling/dysphagia, but, considering their potential side effects, they should remain a secondary choice compared to nonpharmacological therapies.

3.2.2. Treatments under Investigation. Other anticholinergic treatments such as ipratropium bromide spray, transdermal scopolamine, and benztropine have also been investigated for treating drooling/dysphagia [123, 176-178]. However, previous studies on the effectiveness of anticholinergic treatments had failed to conclude on the superiority of one drug over another [179]. The ipratropium bromide spray (which has induced a significant effect on the UPDRS part 6 subscore [178]) is used sublingually as a bronchodilator and does not cross the BBB, thereby reducing systemic side effects [152]. Unfortunately, there is insufficient data about its safety and efficacy to draw definite conclusions on its potential interest in drooling/dysphagia management [51, 123]. Adrenergic receptors agonists have also been explored in this context. Clonidine, a selective $\alpha 2$-adrenergic receptor agonist, significantly improved the frequency at which patients had to clear their mouths $[51,52,152]$. The most common adverse events observed with clonidine were diurnal somnolence (2/17 patients), dizziness (1/17), and dry mouth (1/17) [180]. The $\alpha 1$-adrenergic agonist modafinil has also been reported to exert rather beneficial effects on drooling/dysphagia in PD patients (6/6 patients), although this improvement was mostly related to dysphagia rather than hypersalivation [51, 181]. Moreover, Lloret et al. have investigated tropicamide, a short-acting muscarinic receptor antagonist, in the treatment of drooling/dysphagia. So far, this treatment has shown potential efficacy (33\% average reduction in salivary volume for 16 patients who completed the study) along with a lack of noticeable side effects and no side effects, although the data must still be considered as preliminary [182]. Radiotherapy has also been suggested as a treatment for drooling/dysphagia and studies in this context have shown a significant improvement in symptoms (79\% of patients), an effect that could be maintained for at least one year [183]. Common side effects were xerostomia ( $40 \%$ of patients) and a loss of taste (45\%), which were mostly transient (25\% and $35 \%$, resp.). Regrettably, the success of radiotherapy is largely compromised by its potential to induce neoplasia $[183,184]$. Therefore, this treatment should only be considered when all other options discussed above have proved ineffective. Finally, surgical options such as neurectomy, salivary gland excision, salivary duct ligation or relocation, and DBS have also been explored to ameliorate drooling/dysphagia [50, 118, 184-187]. Neurectomy, that is, the surgical sectioning of the chorda tympani nerves, reduces salivary production (improvement in $74 \%$ of patients) but might induce serious complications such as hearing loss and a loss of taste $[152,188]$. These invasive options (neurectomy and salivary gland/duct surgeries) can be realized individually or in combination (with $>75 \%$ success) and possible adverse effects include dental caries (10\% of patients), cracked lips (10\%), aspiration pneumonia, and xerostomia [152, 184-186]. Due to their high risk of irreversible adverse effects, all these interventions are considered only when all other available options have failed to bring about a positive outcome [32]. DBS intervention has not been studied much to date in the context of drooling/dysphagia improvement, but, with the limited information obtained so far, it seems unlikely that DBS represents a useful option $[51,118]$.

\subsection{Nausea, Vomiting, and Gastroparesis}

3.3.1. Effective Treatments. Despite substantial progress in recent research on constipation and drooling treatment, the armamentarium of useful agents for other PD-associated GI symptoms, such as nausea, vomiting, and gastroparesis, remains severely limited [31]. The effective antiemetic medications that have been investigated so far include domperidone (100\% efficacy) and trimethobenzamide ( 20\% efficacy) $[123,198,199]$. Domperidone is a peripheral DA antagonist that does not cross the BBB and has been reported to safely improve gastroparesis and associated GI symptoms in PD patients [199]. This antiemetic agent is not available in the USA but is prescribed in many other countries across the world $[13,16]$. Interestingly, metoclopramide, another DA receptor antagonist often employed in gastroparesis treatment, is contraindicated for PD patients because it worsens motor symptoms by blocking DA receptors in the CNS [31]. Finally, changes in the lifestyle of patients with nausea, vomiting, and gastroparesis symptoms are also strongly recommended. Thus, having small and frequent meals, avoiding high-fat foods, drinking during meals, and walking after meals are the suggested options [31].

3.3.2. Treatments under Investigation. Other treatments have been considered to improve nausea, vomiting, and gastroparesis in PD patients. Mosapride and cisapride, two mild 5-HT4 serotonin receptor agonists that act as prokinetic agents, have been shown to reduce gastroparesis symptoms in $\mathrm{PD}(3 / 5$ and $8 / 12$ patients, resp.) $[200,201]$. However, due to their cardiotoxicity, these drugs have been removed from the US market [31]. Other potential options such as erythromycin and the implantation of a gastric pacemaker might be beneficial to correct gastroparesis, but they have not yet been specifically tested in PD patients [31]. Furthermore, electric stimulation, surgery, or application of BTX in the pyloric sphincter can be employed, albeit exclusively in extreme cases [16].

3.4. Possible Interactions of PD Treatment with GI Dysfunctions. As mentioned above, treatments for motor symptoms may influence GI symptoms, but the opposite may also hold true [31]. These considerations hamper interpretations as 
to whether symptoms observed in a given patient reflect the disease per se or, on the contrary, are iatrogenic. For instance, L-DOPA is usually administered in combination with carbidopa, which is well known to exacerbate nausea [13]. In the periphery, carbidopa prevents the conversion of L-DOPA to DA, and as its half-life exceeds that of LDOPA, one might theoretically expect residual effects of carbidopa outside the CNS [202]. This treatment might well prevent the conversion of endogenous peripheral L-DOPA in addition to the exogenous L-DOPA that is concomitantly administrated. Such potentially protracted effects of the combination therapy due to putative residual carbidopa could result in decreased DA production in the periphery, which would then affect NMS, including GI features. It has also been shown that carbidopa might influence DA concentrations in the kidney [203]. Therefore, the potential impact of carbidopa on peripheral organs involved in NMS deserves careful evaluation. This concept may be of importance when considering the administration of L-DOPA by intestinal gel infusion, which may act directly on GI tract [202].

\section{Discussion}

Despite increased interest in the recent years in PDassociated NMS, there is still a paucity of knowledge on the GI features of PD. This is an unfortunate state of affairs since these features are more difficult to manage than motor symptoms and are therefore of great concern for parkinsonian patients. In addition to their adverse effects on quality of life, GI problems are even more relevant to the understanding of the etiology of PD, insofar as Braak's hypothesis holds true. Accordingly, by collecting more clinical data on peripheral symptoms in putative cases of PD, an early diagnosis and better preventive action, as well as more efficient management of this disorder at its critical initiation and development stages, might be possible. For the time being, such a therapeutic approach is still purely speculative since PD is diagnosed solely following the recurrent manifestation of motor symptoms. Therefore, inasmuch as the importance of the ENS is further confirmed by future PD research, it might become essential to target the earliest manifestations of the disease in order to delay or even prevent neurodegeneration and thus the apparition of motor symptoms in PD patients.

This review summarizes the range of effective as well as potential therapeutic approaches to the management of GI symptoms in PD patients. Unfortunately, all existing treatments for both motor and nonmotor symptoms are purely symptomatic and result in merely temporary relief of these manifestations. Furthermore, it is very difficult to adequately treat GI symptoms because the exact target remains often unknown due to the lack of basic knowledge on the pathophysiology of the ENS component in the etiology of PD. Indeed, the main objective of current therapeutic research on PD is still oriented towards its management within the limits of present knowledge, that is, mainly reducing the side effects of medication, rather towards the further investigation of $\mathrm{PD}$ pathogenesis.
To date, several hypotheses have been proposed to understand the GI aspects in the physiopathology of PD. The most promising among these hypotheses include neurodegeneration, $\alpha$-syn overexpression, inflammation, intestinal hyperpermeability, and microbiota disturbance as likely mechanisms involved in GI dysfunction [83, 84, 99, 204-208]. Furthermore, some factors have been suggested to participate in the initiation of the PD process, namely, disruption of the lysosomal and proteasomal systems, abnormal autophagy, endoplasmic reticulum stress, mitochondrial dysfunction, and oxidative stress [209-215]. Unfortunately, none of the latter putative factors could be confirmed as a PD biomarker due to the lack of an animal or cellular model that faithfully reproduces all features of PD. In the current state of our basic knowledge on PD pathophysiology, more optimal therapeutic avenues might be obtained by targeting a subset of these elements, given the fact that PD is clearly a multifactorial disease. However, a better insight into the etiology and mechanisms of the disease is crucial in order to find more targeted and effective treatments.

As summarized in the present review, there are now several lines of evidence that clearly demonstrate that GI dysfunctions not only are painful symptoms whose treatment constantly challenges clinicians, but also are relevant to the very process that causes $\mathrm{PD}$, likely as reflections of processes that are under control by the ENS. Thus, GI symptoms in PD definitely should deserve much closer attention and warrant more detailed investigation in order to grasp the causative mechanisms at the core of this complex disease, which is a necessary prelude to the proper management of the disease's symptoms and, ultimately, to an actual curative strategy. Undoubtedly, further critical aspects of the mechanism leading to PD remain to be discovered and should call for a reassessment of the whole medical approach to this devastating disorder. Thus, in view of the recent developments in PD research emphasized in the present coverage of the literature, the peripheral aspects of PD should remain a priority in order to improve the therapeutic approaches to the disease, which are clearly in need of major improvements.

\section{Abbreviations}

$\alpha$-syn: Alpha-synuclein

BBB: Blood-brain barrier

BTX: Botulinum toxin

CNS: Central nervous system

DA: Dopamine

DAergic: Dopaminergic

DBS: Deep brain stimulation

ENS: $\quad$ Enteric nervous system

GI: Gastrointestinal

L-DOPA: Levodopa, L-3,4-dihydroxyphenylalanine

NMS: Nonmotor symptoms

NOS: $\quad$ Nitric oxide synthase

PD: $\quad$ Parkinson's disease

UPDRS: Unified Parkinson's Disease Rating Scale

VIP: Vasoactive intestinal peptide. 


\section{Competing Interests}

The authors declare that there are no competing interests regarding the publication of this paper.

\section{Acknowledgments}

The authors acknowledge the grant support of the Canadian Institute of Health Research (Thérèse Di Paolo and Denis Soulet) and the Canadian Foundation for Innovation (Denis Soulet). Andrée-Anne Poirier holds studentship awards from the Fonds de la Recherche du Québec-Santé (FRQS), Parkinson Québec, Société Parkinson Canada and La Fondation du CHU de Québec (Scholarship Didier-Mouginot). Denis Soulet holds a career award Chercheur-Boursier Junior 2 from Fonds de la Recherche du Québec-Santé (FRQS). The authors also wish to thank Dr. Jaclyn I. Wamsteeker Cusulin (Hoffmann-La Roche, Basel, Switzerland) and Dr. Richard Poulin (Centre de Recherche du CHU de Québec, Québec, Canada) for their critical reading of the manuscript.

\section{References}

[1] J. Parkinson, "An essay on the shaking palsy. 1817," The Journal of Neuropsychiatry \& Clinical Neurosciences, vol. 14, no. 2, pp. 222-236, 2002.

[2] A. J. Lees, "Unresolved issues relating to the Shaking Palsy on the celebration of James Parkinson's 250th birthday," Movement Disorders, vol. 22, supplement 17, pp. S327-S334, 2007.

[3] J. Jankovic, "Parkinson's disease: clinical features and diagnosis," Journal of Neurology, Neurosurgery and Psychiatry, vol. 79, no. 4, pp. 368-376, 2008.

[4] M. W. Hayes, V. S. Fung, T. E. Kimber, and J. D. O’Sullivan, "Current concepts in the management of Parkinson disease," Medical Journal of Australia, vol. 192, no. 3, pp. 144-149, 2010.

[5] J. G. Goldman and R. Postuma, "Premotor and nonmotor features of Parkinson's disease," Current Opinion in Neurology, vol. 27, no. 4, pp. 434-441, 2014.

[6] A. Sauerbier and K. R. Chaudhuri, "Non-motor symptoms: the core of multi-morbid Parkinson's disease," British Journal of Hospital Medicine, vol. 75, no. 1, pp. 18-24, 2014.

[7] A. Park and M. Stacy, "Non-motor symptoms in Parkinson's disease," Journal of Neurology, vol. 256, supplement 3, pp. 293298, 2009.

[8] K. R. Chaudhuri and A. H. Schapira, "Non-motor symptoms of Parkinson's disease: dopaminergic pathophysiology and treatment," The Lancet Neurology, vol. 8, no. 5, pp. 464-474, 2009.

[9] R. Pahwa and K. E. Lyons, "Early diagnosis of Parkinson's disease: recommendations from diagnostic clinical guidelines," The American Journal of Managed Care, vol. 16, pp. S94-S99, 2010.

[10] M. Horstink, E. Tolosa, U. Bonuccelli et al., "Review of the therapeutic management of Parkinson's disease. Report of a joint task force of the European Federation of Neurological Societies and the Movement Disorder Society-European Section-part I: early (uncomplicated) Parkinson's disease," European Journal of Neurology, vol. 13, no. 11, pp. 1170-1185, 2006.

[11] S. Krishnan, G. Sarma, S. Sarma, and A. Kishore, "Do nonmotor symptoms in Parkinson's disease differ from normal aging?" Movement Disorders, vol. 26, no. 11, pp. 2110-2113, 2011.
[12] D. A. Gallagher, A. J. Lees, and A. Schrag, "What are the most important nonmotor symptoms in patients with Parkinson's disease and are we missing them?" Movement Disorders, vol. 25, no. 15, pp. 2493-2500, 2010.

[13] K. E. Lyons and R. Pahwa, "The impact and management of nonmotor symptoms of Parkinson's disease," American Journal of Managed Care, pp. S308-S314, 2011.

[14] S.-E. Soh, M. E. Morris, and J. L. McGinley, "Determinants of health-related quality of life in Parkinson's disease: a systematic review," Parkinsonism and Related Disorders, vol. 17, no. 1, pp. $1-9,2011$.

[15] A. Todorova, P. Jenner, and K. Ray Chaudhuri, "Non-motor parkinson's: integral to motor parkinson's, yet often neglected," Practical Neurology, vol. 14, no. 5, pp. 310-322, 2014.

[16] O. Bernal-Pacheco, N. Limotai, C. L. Go, and H. H. Fernandez, "Nonmotor manifestations in parkinson disease," Neurologist, vol. 18, no. 1, pp. 1-16, 2012.

[17] A. Todorova and K. Ray Chaudhuri, "Subcutaneous apomorphine and non-motor symptoms in Parkinson's disease," Parkinsonism and Related Disorders, vol. 19, no. 12, pp. 10731078, 2013.

[18] D. Berg, R. B. Postuma, B. Bloem et al., "Time to redefine PD? Introductory statement of the MDS Task Force on the definition of Parkinson's disease," Movement Disorders, vol. 29, no. 4, pp. 454-462, 2014.

[19] A. Siderowf and A. E. Lang, "Premotor Parkinson's disease: concepts and definitions," Movement Disorders, vol. 27, no. 5, pp. 608-616, 2012.

[20] M. B. Stern, A. Lang, and W. Poewe, "Toward a redefinition of Parkinson's disease," Movement Disorders, vol. 27, no. 1, pp. 5460, 2012.

[21] K. A. Jellinger, "Neuropathology of sporadic Parkinson's disease: evaluation and changes of concepts," Movement Disorders, vol. 27, no. 1, pp. 8-30, 2012.

[22] H. Braak, U. Rüb, W. P. Gai, and K. Del Tredici, "Idiopathic Parkinson's disease: possible routes by which vulnerable neuronal types may be subject to neuroinvasion by an unknown pathogen," Journal of Neural Transmission, vol. 110, no. 5, pp. 517-536, 2003.

[23] H. Braak, E. Ghebremedhin, U. Rüb, H. Bratzke, and K. Del Tredici, "Stages in the development of Parkinson's diseaserelated pathology," Cell and Tissue Research, vol. 318, no. 1, pp. 121-134, 2004.

[24] K. A. Jellinger, "In dementia with lewy bodies, braak stage determines phenotype, not lewy body distribution," Neurology, vol. 70, no. 5, pp. 407-408, 2008.

[25] R. J. Phillips, G. C. Walter, S. L. Wilder, E. A. Baronowsky, and T. L. Powley, "Alpha-synuclein-immunopositive myenteric neurons and vagal preganglionic terminals: autonomic pathway implicated in Parkinson's disease?" Neuroscience, vol. 153, no. 3, pp. 733-750, 2008.

[26] M. G. Cersosimo and E. E. Benarroch, "Pathological correlates of gastrointestinal dysfunction in Parkinson's disease," Neurobiology of Disease, vol. 46, no. 3, pp. 559-564, 2012.

[27] S. Holmqvist, O. Chutna, L. Bousset et al., "Direct evidence of Parkinson pathology spread from the gastrointestinal tract to the brain in rats," Acta Neuropathologica, vol. 128, no. 6, pp. 805820, 2014.

[28] M. Stacy, "Nonmotor symptoms in Parkinson's disease," International Journal of Neuroscience, vol. 121, supplement 2, pp. 9-17, 2011. 
[29] K. R. Chaudhuri, P. Martinez-Martin, R. G. Brown et al., "The metric properties of a novel non-motor symptoms scale for Parkinson's disease: results from an international pilot study," Movement Disorders, vol. 22, no. 13, pp. 1901-1911, 2007.

[30] T. A. Zesiewicz, K. L. Sullivan, I. Arnulf et al., "Practice parameter: treatment of nonmotor symptoms of Parkinson disease: report of the quality standards subcommittee of the American academy of neurology," Neurology, vol. 74, no. 11, pp. 924-931, 2010.

[31] L. J. Cloud and J. G. Greene, "Gastrointestinal features of Parkinson's disease," Current Neurology and Neuroscience Reports, vol. 11, no. 4, pp. 379-384, 2011.

[32] J. S. Dubow, "Autonomic dysfunction in Parkinson's disease," Disease-a-Month, vol. 53, no. 5, pp. 265-274, 2007.

[33] P. Barone, A. Antonini, C. Colosimo et al., "The PRIAMO study: a multicenter assessment of nonmotor symptoms and their impact on quality of life in Parkinson's disease," Movement Disorders, vol. 24, no. 11, pp. 1641-1649, 2009.

[34] O. Guneysel, O. Onultan, and O. Onur, "Parkinson's disease and the frequent reasons for emergency admission," Neuropsychiatric Disease and Treatment, vol. 4, no. 4, pp. 711-714, 2008.

[35] J. M. Sheard, S. Ash, G. D. Mellick, P. A. Silburn, and G. K. Kerr, "Malnutrition in a sample of community-dwelling people with Parkinson's disease," PLoS ONE, vol. 8, no. 1, Article ID e53290, 2013.

[36] D. Martinez-Ramirez, L. Almeida, J. C. Giugni et al., "Rate of aspiration pneumonia in hospitalized Parkinson's disease patients: a cross-sectional study," BMC Neurology, vol. 15, article 104, 2015

[37] W. H. Jost, "Gastrointestinal motility problems in patients with Parkinson's disease. Effects of antiparkinsonian treatment and guidelines for management," Drugs and Aging, vol. 10, no. 4, pp. 249-258, 1997.

[38] C. Bozek and S. M. Calne, "The management of medical and surgical problems in Parkinson's disease," BC Medical Journal, vol. 43, no. 4, pp. 219-223, 2001.

[39] S. Marrinan, A. V. Emmanuel, and D. J. Burn, "Delayed gastric emptying in Parkinson's disease," Movement Disorders, vol. 29, no. 1, pp. 23-32, 2014.

[40] P. Derkinderen, T. Rouaud, T. Lebouvier, S. Bruley Des Varannes, M. Neunlist, and R. De Giorgio, "Parkinson disease: the enteric nervous system spills its guts," Neurology, vol. 77, no. 19, pp. 1761-1767, 2011.

[41] T. Lebouvier, T. Chaumette, S. Paillusson et al., "The second brain and Parkinson's disease," European Journal of Neuroscience, vol. 30, no. 5, pp. 735-741, 2009.

[42] M. Schemann and M. Neunlist, "The human enteric nervous system," Neurogastroenterology and Motility, vol. 16, supplement 1, pp. 55-59, 2004.

[43] R. D. Abbott, H. Petrovitch, L. R. White et al., "Frequency of bowel movements and the future risk of Parkinson's disease," Neurology, vol. 57, no. 3, pp. 456-462, 2001.

[44] U. Wüllner, T. Schmitz-Hübsch, G. Antony et al., "Autonomic dysfunction in 3414 Parkinson's disease patients enrolled in the German Network on Parkinson's disease (KNP e.V.): the effect of ageing," European Journal of Neurology, vol. 14, no. 12, pp. 14051408, 2007.

[45] R. Postuma, S. R. Romenets, and R. Rakheja, Physician Guide: Non-Motor Symptoms of Parkinson's Disease, McGill University Health Centre, Montreal, Canada, 2012.
[46] E. Y. Uc, M. P. McDermott, K. S. Marder et al., "Incidence of and risk factors for cognitive impairment in an early Parkinson disease clinical trial cohort," Neurology, vol. 73, no. 18, pp. 14691477, 2009.

[47] R. Sakakibara, M. Kishi, E. Ogawa et al., "Bladder, bowel, and sexual dysfunction in Parkinson's disease," Parkinson's Disease, vol. 2011, Article ID 924605, 21 pages, 2011.

[48] S. Toebosch, V. Tudyka, A. Masclee, and G. Koek, "Treatment of recurrent sigmoid volvulus in Parkinson's disease by percutaneous endoscopic colostomy," World Journal of Gastroenterology, vol. 18, no. 40, pp. 5812-5815, 2012.

[49] B. T. Johnston, Q. Li, J. A. Castell, and D. O. Castell, "Swallowing and esophageal function in Parkinson's disease," The American Journal of Gastroenterology, vol. 90, no. 10, pp. 1741-1746, 1995.

[50] W. G. Ondo, C. Hunter, and W. Moore, "A double-blind placebo-controlled trial of botulinum toxin B for sialorrhea in Parkinson's disease," Neurology, vol. 62, no. 1, pp. 37-40, 2004.

[51] P. Srivanitchapoom, S. Pandey, and M. Hallett, "Drooling in Parkinson's disease: a review," Parkinsonism \& Related Disorders, vol. 20, no. 11, pp. 1109-1118, 2014.

[52] S. Perez-Lloret, M. V. Rey, A. Pavy-Le Traon, and O. Rascol, "Emerging drugs for autonomic dysfunction in Parkinson's disease," Expert Opinion on Emerging Drugs, vol. 18, no. 1, pp. 39-53, 2013.

[53] O. Dogu, D. Apaydin, S. Sevim, D. U. Talas, and M. Aral, "Ultrasound-guided versus 'blind' intraparotid injections of botulinum toxin-A for the treatment of sialorrhoea in patients with Parkinson's disease," Clinical Neurology and Neurosurgery, vol. 106, no. 2, pp. 93-96, 2004.

[54] M. L. Evatt, K. R. Chaudhuri, K. L. Chou et al., "Dysautonomia rating scales in Parkinson's disease: sialorrhea, dysphagia, and constipation-critique and recommendations by movement disorders task force on rating scales for Parkinson's disease," Movement Disorders, vol. 24, no. 5, pp. 635-646, 2009.

[55] S. P. Lloret, G. P. Arce, M. Rossi, M. L. C. Nemet, P. Salsamendi, and M. Merello, "Validation of a new scale for the evaluation of sialorrhea in patients with Parkinson's disease," Movement Disorders, vol. 22, no. 1, pp. 107-111, 2007.

[56] M. Proulx, F. P. de Courval, M. A. Wiseman, and M. Panisset, "Salivary production in Parkinson's disease," Movement Disorders, vol. 20, no. 2, pp. 204-207, 2005.

[57] O. R. Tumilasci, M. G. Cersósimo, J. E. Belforte, F. E. Micheli, E. E. Benarroch, and J. H. Pazo, "Quantitative study of salivary secretion in Parkinson's disease," Movement Disorders, vol. 21, no. 5, pp. 660-667, 2006.

[58] A. C. Nóbrega, B. Rodrigues, A. C. Torres, R. D. Scarpel, C. A. Neves, and A. Melo, "Is drooling secondary to a swallowing disorder in patients with Parkinson's disease?" Parkinsonism and Related Disorders, vol. 14, no. 3, pp. 243-245, 2008.

[59] J. Leibner, A. Ramjit, L. Sedig et al., "The impact of and the factors associated with drooling in Parkinson's disease," Parkinsonism and Related Disorders, vol. 16, no. 7, pp. 475-477, 2010.

[60] S.-M. Cheon, M.-S. Ha, M. J. Park, and J. W. Kim, "Nonmotor symptoms of Parkinson's disease: prevalence and awareness of patients and families," Parkinsonism and Related Disorders, vol. 14, no. 4, pp. 286-290, 2008.

[61] J. G. Kalf, A. M. Smit, B. R. Bloem, M. J. Zwarts, and M. Munneke, "Impact of drooling in Parkinson's disease," Journal of Neurology, vol. 254, no. 9, pp. 1227-1232, 2007. 
[62] A. Q. Rana, M. S. Yousuf, N. Awan, and A. Fattah, "Impact of progression of Parkinson's disease on drooling in various ethnic groups," European Neurology, vol. 67, no. 5, pp. 312-314, 2012.

[63] B. Müller, J. P. Larsen, T. Wentzel-Larsen, G. O. Skeie, and O.-B. Tysnes, "Autonomic and sensory symptoms and signs in incident, untreated Parkinson's disease: frequent but mild," Movement Disorders, vol. 26, no. 1, pp. 65-72, 2011.

[64] K. Del Tredici, C. H. Hawkes, E. Ghebremedhin, and H. Braak, "Lewy pathology in the submandibular gland of individuals with incidental Lewy body disease and sporadic Parkinson's disease," Acta Neuropathologica, vol. 119, no. 6, pp. 703-713, 2010.

[65] A. Kikuchi, T. Baba, T. Hasegawa et al., "Hypometabolism in the supplementary and anterior cingulate cortices is related to dysphagia in Parkinson's disease: a cross-sectional and 3-year longitudinal cohort study," BMJ Open, vol. 3, no. 3, Article ID 002249, 2013.

[66] A. Potulska, A. Friedman, L. Królicki, and A. Spychala, "Swallowing disorders in Parkinson's disease," Parkinsonism and Related Disorders, vol. 9, no. 6, pp. 349-353, 2003.

[67] R. F. Pfeiffer, "Gastrointestinal dysfunction in Parkinson's disease," The Lancet Neurology, vol. 2, no. 2, pp. 107-116, 2003.

[68] J. G. Kalf, B. J. M. de Swart, B. R. Bloem, and M. Munneke, "Prevalence of oropharyngeal dysphagia in Parkinson's disease: a meta-analysis," Parkinsonism and Related Disorders, vol. 18, no. 4, pp. 311-315, 2012.

[69] J. L. Fuh, R.-C. Lee, S.-J. Wang et al., "Swallowing difficulty in Parkinson's disease," Clinical Neurology and Neurosurgery, vol. 99, no. 2, pp. 106-112, 1997.

[70] G. N. Ali, K. L. Wallace, R. Schwartz, D. J. DeCarle, A. S. Zagami, and I. J. Cook, "Mechanisms of oral-pharyngeal dysphagia in patients with Parkinson's disease," Gastroenterology, vol. 110, no. 2, pp. 383-392, 1996.

[71] S. Varanese, Z. Birnbaum, R. Rossi, and A. Di Rocco, "Treatment of advanced Parkinson's disease," Parkinson's Disease, vol. 2010, Article ID 480260, 9 pages, 2010.

[72] L. Edwards, E. M. M. Quigley, R. Hofman, and R. F. Pfeiffer, "Gastrointestinal symptoms in Parkinson disease: 18-month follow-up study," Movement Disorders, vol. 8, no. 1, pp. 83-86, 1993.

[73] L. L. Edwards, R. F. Pfeiffer, E. M. M. Quigley, R. Hofman, and M. Balluff, "Gastrointestinal symptoms in Parkinson's disease," Movement Disorders, vol. 6, no. 2, pp. 151-156, 1991.

[74] Z. S. Heetun and E. M. Quigley, "Gastroparesis and Parkinson's disease: a systematic review," Parkinsonism and Related Disorders, vol. 18, no. 5, pp. 433-440, 2012.

[75] R. Hardoff, M. Sula, A. Tamir et al., "Gastric emptying time and gastric motility in patients with Parkinson's disease," Movement Disorders, vol. 16, no. 6, pp. 1041-1047, 2001.

[76] O. Goetze, A. B. Nikodem, J. Wiezcorek et al., "Predictors of gastric emptying in Parkinson's disease," Neurogastroenterology and Motility, vol. 18, no. 5, pp. 369-375, 2006.

[77] K. Wakabayashi and H. Takahashi, "Neuropathology of autonomic nervous system in Parkinson's disease," European Neurology, vol. 38, no. 2, pp. 2-7, 1997.

[78] E. E. Benarroch, A. M. Schmeichel, P. Sandroni, P. A. Low, and J. E. Parisi, "Involvement of vagal autonomic nuclei in multiple system atrophy and Lewy body disease," Neurology, vol. 66, no. 3, pp. 378-383, 2006.

[79] T. G. Beach, C. H. Adler, L. I. Sue et al., "Multi-organ distribution of phosphorylated $\alpha$-synuclein histopathology in subjects with Lewy body disorders," Acta Neuropathologica, vol. 119, no. 6, pp. 689-702, 2010.

[80] S. J. Qualman, H. M. Haupt, P. Yang, and S. R. Hamilton, "Esophageal Lewy bodies associated with ganglion cell loss in achalasia. Similarity to Parkinson's disease," Gastroenterology, vol. 87, no. 4, pp. 848-856, 1984.

[81] W. J. Kupsky, M. M. Grimes, J. Sweeting, R. Bertsch, and L. J. Cote, "Parkinson's disease and megacolon: concentric hyaline inclusions (lewy bodies) in enteric ganglion cells," Neurology, vol. 37, no. 7, pp. 1253-1255, 1987.

[82] K. Wakabayashi, H. Takahashi, S. Takeda, E. Ohama, and F. Ikuta, "Parkinson's disease: the presence of Lewy bodies in Auerbach's and Meissner's plexuses," Acta Neuropathologica, vol. 76, no. 3, pp. 217-221, 1988.

[83] K. Wakabayashi, H. Takahashi, E. Ohama, and F. Ikuta, "Parkinson's disease: an immunohistochemical study of Lewy body-containing neurons in the enteric nervous system," Acta Neuropathologica, vol. 79, no. 6, pp. 581-583, 1990.

[84] H. Braak, R. A. I. De Vos, J. Bohl, and K. Del Tredici, "Gastric $\alpha$-synuclein immunoreactive inclusions in Meissner's and Auerbach's plexuses in cases staged for Parkinson's diseaserelated brain pathology," Neuroscience Letters, vol. 396, no. 1, pp. 67-72, 2006.

[85] D. Hilton, M. Stephens, L. Kirk et al., "Accumulation of $\alpha$ synuclein in the bowel of patients in the pre-clinical phase of Parkinson's disease," Acta Neuropathologica, vol. 127, no. 2, pp. 235-241, 2014.

[86] K. M. Shannon, A. Keshavarzian, E. Mutlu et al., " $\alpha$-synuclein in colonic submucosa in early untreated Parkinson's disease," Movement Disorders, vol. 27, no. 6, pp. 709-715, 2012.

[87] A. Gold, Z. T. Turkalp, and D. G. Munoz, "Enteric alphasynuclein expression is increased in Parkinson's disease but not Alzheimer's disease," Movement Disorders, vol. 28, no. 2, pp. 237-241, 2013.

[88] T. Lebouvier, E. Coron, T. Chaumette et al., "Routine colonic biopsies as a new tool to study the enteric nervous system in living patients," Neurogastroenterology and Motility, vol. 22, no. 1, pp. el1-e14, 2010.

[89] T. Lebouvier, M. Neunlist, S. B. des Varannes et al., "Colonic biopsies to assess the neuropathology of Parkinson's disease and its relationship with symptoms," PLoS ONE, vol. 5, no. 9, Article ID e12728, 2010.

[90] H. Pouclet, T. Lebouvier, E. Coron et al., "A comparison between rectal and colonic biopsies to detect Lewy pathology in Parkinson's disease," Neurobiology of Disease, vol. 45, no. 1, pp. 305-309, 2012.

[91] H. Pouclet, T. Lebouvier, E. Coron, S. B. Des Varannes, M. Neunlist, and P. Derkinderen, "A comparison between colonic submucosa and mucosa to detect Lewy pathology in Parkinson's disease," Neurogastroenterology and Motility, vol. 24, no. 4, pp. e202-e205, 2012.

[92] D. M. Annerino, S. Arshad, G. M. Taylor, C. H. Adler, T. G. Beach, and J. G. Greene, "Parkinson's disease is not associated with gastrointestinal myenteric ganglion neuron loss," Acta Neuropathologica, vol. 124, no. 5, pp. 665-680, 2012.

[93] E. Gelpi, J. Navarro-Otano, E. Tolosa et al., "Multiple organ involvement by alpha-synuclein pathology in lewy body disorders," Movement Disorders, vol. 29, no. 8, pp. 1010-1018, 2014.

[94] D. E. Reed and S. J. Vanner, "Long vasodilator reflexes projecting through the myenteric plexus in guinea-pig ileum," Journal of Physiology, vol. 553, no. 3, pp. 911-924, 2003. 
[95] A. Corbillé, F. Letournel, J. H. Kordower et al., "Evaluation of alpha-synuclein immunohistochemical methods for the detection of Lewy-type synucleinopathy in gastrointestinal biopsies," Acta Neuropathologica Communications, vol. 4, p. 35, 2016.

[96] T. G. Beach, A. Corbillé, F. Letournel et al., "Multicenter assessment of immunohistochemical methods for pathological $\alpha$-synuclein in sigmoid colon of autopsied Parkinson's disease and control subjects," Journal of Parkinson's Disease, vol. 6, no. 4, pp. 761-770, 2016.

[97] Y.-M. Kuo, Z. Li, Y. Jiao et al., "Extensive enteric nervous system abnormalities in mice transgenic for artificial chromosomes containing Parkinson disease-associated $\alpha$-synuclein gene mutations precede central nervous system changes," Human Molecular Genetics, vol. 19, no. 9, Article ID ddq038, pp. 1633-1650, 2010.

[98] R. Sakakibara, T. Uchiyama, T. Yamanishi, K. Shirai, and T. Hattori, "Bladder and bowel dysfunction in Parkinson's disease," Journal of Neural Transmission, vol. 115, no. 3, pp. 443-460, 2008.

[99] C. Singaram, E. A. Gaumnitz, C. Torbey et al., "Dopaminergic defect of enteric nervous system in Parkinson's disease patients with chronic constipation," The Lancet, vol. 346, no. 8979, pp. 861-864, 1995.

[100] T. Wedel, J. Spiegler, S. Soellner et al., "Enteric nerves and interstitial cells of Cajal are altered in patients with slow-transit constipation and megacolon," Gastroenterology, vol. 123, no. 5, pp. 1459-1467, 2002.

[101] M. Camilleri, T. Cowen, and T. R. Koch, "Enteric neurodegeneration in ageing," Neurogastroenterology and Motility, vol. 20, no. 4, pp. 418-429, 2008.

[102] T. Lebouvier, T. Chaumette, P. Damier et al., "Pathological lesions in colonic biopsies during Parkinson's disease," Gut, vol. 57, no. 12, pp. 1741-1743, 2008.

[103] A.-G. Corbillé, E. Coron, M. Neunlist, P. Derkinderen, and T. Lebouvier, "Appraisal of the dopaminergic and noradrenergic innervation of the submucosal plexus in PD," Journal of Parkinson's Disease, vol. 4, no. 4, pp. 571-576, 2014.

[104] G. Anderson, A. R. Noorian, G. Taylor et al., "Loss of enteric dopaminergic neurons and associated changes in colon motility in an MPTP mouse model of Parkinson's disease," Experimental Neurology, vol. 207, no. 1, pp. 4-12, 2007.

[105] M. Côté, J. Drouin-Ouellet, F. Cicchetti, and D. Soulet, “The critical role of the MyD88-dependent pathway in non-CNS MPTP-mediated toxicity," Brain, Behavior, and Immunity, vol. 25, no. 6, pp. 1143-1152, 2011.

[106] T. Chaumette, T. Lebouvier, P. Aubert et al., "Neurochemical plasticity in the enteric nervous system of a primate animal model of experimental Parkinsonism," Neurogastroenterology and Motility, vol. 21, no. 2, pp. 215-222, 2009.

[107] F. Blandini, B. Balestra, G. Levandis et al., "Functional and neurochemical changes of the gastrointestinal tract in a rodent model of Parkinson's disease," Neuroscience Letters, vol. 467, no. 3, pp. 203-207, 2009.

[108] H. C. Zhu, J. Zhao, C. Y. Luo, and Q. Q. Li, “Gastrointestinal dysfunction in a Parkinson's disease rat model and the changes of dopaminergic, nitric oxidergic, and cholinergic neurotransmitters in myenteric plexus," Journal of Molecular Neuroscience, vol. 47, no. 1, pp. 15-25, 2012.

[109] F. Blandini, M.-T. Armentero, and E. Martignoni, "The 6hydroxydopamine model: news from the past," Parkinsonism and Related Disorders, vol. 14, no. 2, pp. S124-S129, 2008.
[110] J. G. Greene, A. R. Noorian, and S. Srinivasan, "Delayed gastric emptying and enteric nervous system dysfunction in the rotenone model of Parkinson's disease," Experimental Neurology, vol. 218, no. 1, pp. 154-161, 2009.

[111] R. B. Banati, S. E. Daniel, and S. B. Blunt, "Glial pathology but absence of apoptotic nigral neurons in long-standing Parkinson's disease," Movement Disorders, vol. 13, no. 2, pp. 221227, 1998

[112] F. Tison, L. Wiart, M. Guatterie et al., "Effects of central dopaminergic stimulation by apomorphine on swallowing disorders in Parkinson's disease," Movement Disorders, vol. 11, no. 6, pp. 729-732, 1996.

[113] I. Strauss, S. K. Kalia, and A. M. Lozano, "Where are we with surgical therapies for Parkinson's disease?" Parkinsonism and Related Disorders, vol. 20, no. 1, pp. S187-S191, 2014.

[114] A. Wagle Shukla and M. S. Okun, "Surgical treatment of Parkinson's disease: patients, targets, devices, and approaches," Neurotherapeutics, vol. 11, no. 1, pp. 47-59, 2014.

[115] M. R. Ciucci, J. M. Barkmeier-Kraemer, and S. J. Sherman, "Subthalamic nucleus deep brain stimulation improves deglutition in Parkinson's disease," Movement Disorders, vol. 23, no. 5, pp. 676-683, 2008.

[116] K. Ashkan, M. Samuel, P. Reddy, and K. Ray Chaudhuri, “The impact of deep brain stimulation on the nonmotor symptoms of Parkinson's disease," Journal of Neural Transmission, vol. 120, no. 4, pp. 639-642, 2013.

[117] M. Zibetti, E. Torre, A. Cinquepalmi et al., "Motor and nonmotor symptom follow-up in Parkinsonian patients after deep brain stimulation of the subthalamic nucleus," European Neurology, vol. 58, no. 4, pp. 218-223, 2007.

[118] M. S. Troche, A. E. Brandimore, K. D. Foote et al., "Swallowing outcomes following unilateral STN vs. GPi surgery: a retrospective analysis," Dysphagia, vol. 29, no. 4, pp. 425-431, 2014.

[119] M. S. Troche, A. E. Brandimore, K. D. Foote, and M. S. Okun, "Swallowing and deep brain stimulation in Parkinson's disease: a systematic review," Parkinsonism and Related Disorders, vol. 19, no. 9, pp. 783-788, 2013.

[120] R. Djaldetti, J. Baron, I. Ziv, and E. Melamed, "Gastric emptying in Parkinson's disease: patients with and without response fluctuations," Neurology, vol. 46, no. 4, pp. 1051-1054, 1996.

[121] T. E. Eichhorn and W. H. Oertel, "Macrogol 3350/electrolyte improves constipation in parkinson's disease and multiple system atrophy," Movement Disorders, vol. 16, no. 6, pp. 11761177, 2001.

[122] M. Coggrave, C. Norton, and J. D. Cody, "Management of faecal incontinence and constipation in adults with central neurological diseases," The Cochrane Database of Systematic Reviews, vol. 1, Article ID CD002115, 2014.

[123] K. Seppi, D. Weintraub, M. Coelho et al., "The movement disorder society evidence-based medicine review update: treatments for the non-motor symptoms of Parkinson's disease," Movement Disorders, vol. 26, supplement 3, pp. S42-S80, 2011.

[124] C. Friedrich, E. Richter, D. Trommeshauser et al., "Absence of excretion of the active moiety of bisacodyl and sodium picosulfate into human breast milk: an open-label, parallelgroup, multiple-dose study in healthy lactating women," Drug Metabolism and Pharmacokinetics, vol. 26, no. 5, pp. 458-464, 2011.

[125] W. Ashraf, R. F. Pfeiffer, F. Park, J. Lof, and E. M. M. Quigley, "Constipation in Parkinson's disease: objective assessment and response to psyllium," Movement Disorders, vol. 12, no. 6, pp. 946-951, 1997. 
[126] W. G. Ondo, C. Kenney, K. Sullivan et al., "Placebo-controlled trial of lubiprostone for constipation associated with Parkinson disease," Neurology, vol. 78, no. 21, pp. 1650-1654, 2012.

[127] J. F. Johanson and R. Ueno, "Lubiprostone, a locally acting chloride channel activator, in adult patients with chronic constipation: a double-blind, placebo-controlled, dose-ranging study to evaluate efficacy and safety," Alimentary Pharmacology and Therapeutics, vol. 25, no. 11, pp. 1351-1361, 2007.

[128] R. K. Portenoy, J. Thomas, M. L. Moehl Boatwright et al., "Subcutaneous methylnaltrexone for the treatment of opioidinduced constipation in patients with advanced illness: A Double-Blind, Randomized, Parallel Group, Dose-Ranging Study," Journal of Pain and Symptom Management, vol. 35, no. 5, pp. 458-468, 2008.

[129] R. Sood and A. C. Ford, "Linaclotide: new mechanisms and new promise for treatment in constipation and irritable bowel syndrome," Therapeutic Advances in Chronic Disease, vol. 4, no. 6, pp. 268-276, 2013.

[130] A. J. Lembo, H. A. Schneier, S. J. Shiff et al., "Two randomized trials of linaclotide for chronic constipation," The New England Journal of Medicine, vol. 365, no. 6, pp. 527-536, 2011.

[131] L. L. Edwards, E. M. M. Quigley, R. K. Harned, R. Hofman, and R. F. Pfeiffer, "Defecatory function in Parkinson's disease: response to apomorphine," Annals of Neurology, vol. 33, no. 5, pp. 490-493, 1993.

[132] S. E. Mathers, P. A. Kempster, P. J. Law et al., "Anal sphincter dysfunction in Parkinson's disease," Archives of Neurology, vol. 46, no. 10, pp. 1061-1064, 1989.

[133] D. Deleu, Y. Hanssens, and M. G. Northway, "Subcutaneous apomorphine: an evidence-based review of its use in Parkinson's disease," Drugs \& Aging, vol. 21, no. 11, pp. 687-709, 2004.

[134] G. U. Corsini, M. D. Zompo, G. L. Gessa, and A. Mangoni, "Therapeutic efficacy of apomorphine combined with an extracerebral inhibitor of dopamine receptors in Parkinson's disease," The Lancet, vol. 313, no. 8123, pp. 954-956, 1979.

[135] P. Reddy, P. Martinez-Martin, A. Rizos et al., "Intrajejunal levodopa versus conventional therapy in parkinson disease: motor and nonmotor effects," Clinical Neuropharmacology, vol. 35, no. 5, pp. 205-207, 2012.

[136] H. Honig, A. Antonini, P. Martinez-Martin et al., "Intrajejunal levodopa infusion in Parkinson's disease: a pilot multicenter study of effects on nonmotor symptoms and quality of life," Movement Disorders, vol. 24, no. 10, pp. 1468-1474, 2009.

[137] S. H. Fox, J. M. Brotchie, and A. E. Lang, "Non-dopaminergic treatments in development for Parkinson's disease," The Lancet Neurology, vol. 7, no. 10, pp. 927-938, 2008.

[138] P. G. Leclere, N. H. Prins, J. A. J. Schuurkes, and R. A. Lefebvre, "5-HT4 receptors located on cholinergic nerves in human colon circular muscle," Neurogastroenterology and Motility, vol. 17, no. 3, pp. 366-375, 2005.

[139] R. A. Lefebvre, S. Ferrero, I. Van Colen et al., "Influence of 5-HT4 receptor activation on acetylcholine release in human large intestine with endometriosis," Neurogastroenterology and Motility, vol. 22, no. 5, pp. 557-563, 2010.

[140] Z. Liu, R. Sakakibara, T. Odaka et al., "Mosapride citrate, a novel 5-HT4 agonist and partial 5-HT3 antagonist, amerliorates constipation in Parkinsonian patients," Movement Disorders, vol. 20, no. 6, pp. 680-686, 2005.

[141] J. C. Morgan and K. D. Sethi, "Tegaserod in constipation associated with Parkinson disease," Clinical Neuropharmacology, vol. 30, no. 1, pp. 52-54, 2007.
[142] L. Degen, C. Petrig, D. Studer, S. Schroller, and C. Beglinger, "Effect of tegaserod on gut transit in male and female subjects," Neurogastroenterology and Motility, vol. 17, no. 6, pp. 821-826, 2005.

[143] P. Pare, R. Bridges, M. C. Champion et al., "Recommendations on chronic constipation (including constipation associated with irritable bowel syndrome) treatment," Canadian Journal of Gastroenterology, vol. 21, pp. 3B-22B, 2007.

[144] Y. Kii, K. Nakatsuji, I. Nose, M. Yabuuchi, Y. Mizuki, and T. Ito, "Effects of 5-HT(4) receptor agonists, cisapride and mosapride citrate on electrocardiogram in anaesthetized rats and guineapigs and conscious cats," Pharmacology \& Toxicology, vol. 89, no. 2, pp. 96-103, 2001.

[145] P. J. H. Tooley, P. Vervaet, and E. Wager, "Cardiac arrhythmias reported during treatment with cisapride," Pharmacoepidemiology and Drug Safety, vol. 8, no. 1, pp. 57-58, 1999.

[146] T. P. Roarty, F. Weber, I. Soykan, and R. W. McCallum, "Misoprostol in the treatment of chronic refractory constipation: results of a long-term open label trial," Alimentary Pharmacology and Therapeutics, vol. 11, no. 6, pp. 1059-1066, 1997.

[147] A. S. Rubiales, S. Hernansanz, C. Gutiérrez, M. L. del Valle, and L. A. Flores, "Neostigmine for refractory constipation in advanced cancer patients," Journal of Pain and Symptom Management, vol. 32, no. 3, pp. 204-205, 2006.

[148] P. A. Cann, N. W. Read, and C. D. Holdsworth, "Oral domperidone: double blind comparison with placebo in irritable bowel syndrome," Gut, vol. 24, no. 12, pp. 1135-1140, 1983.

[149] S. C. Reddymasu, I. Soykan, and R. W. McCallum, "Domperidone: review of pharmacology and clinical applications in gastroenterology," American Journal of Gastroenterology, vol. 102, no. 9, pp. 2036-2045, 2007.

[150] H. P. Parkman, S. S. C. Rao, J. C. Reynolds et al., "Neurotrophin3 improves functional constipation," The American Journal of Gastroenterology, vol. 98, no. 6, pp. 1338-1347, 2003.

[151] R. F. Pfeiffer, K. Markopoulou, E. M. M. Quigley, N. Stambler, and J. M. Cedarbaum, "Effect of NT-3 on bowel function in Parkinson's disease," Movement Disorders, vol. 17, supplement 5, pp. S218-S263 (P714), 2002.

[152] K. L. Chou, M. Evatt, V. Hinson, and K. Kompoliti, "Sialorrhea in Parkinson's disease: a review," Movement Disorders, vol. 22, no. 16, pp. 2306-2313, 2007.

[153] A. Albanese, G. Maria, A. Bentivoglio, G. Brisinda, E. Cassetta, and P. Tonali, "Severe constipation in Parkinson's disease relieved by botulinum toxin," Movement Disorders, vol. 12, no. 5, pp. 764-766, 1997.

[154] F. Cadeddu, A. R. Bentivoglio, F. Brandara, G. Marniga, G. Brisinda, and G. Maria, "Outlet type constipation in Parkinson's disease: results of botulinum toxin treatment," Alimentary Pharmacology and Therapeutics, vol. 22, no. 10, pp. 997-1003, 2005.

[155] K. J. Lee, J. H. Kim, and S. W. Cho, "Short-term effects of magnetic sacral dermatome stimulation for idiopathic slow transit constipation: sham-controlled, cross-over pilot study," Journal of Gastroenterology and Hepatology, vol. 21, no. 1, pp. 4753, 2006.

[156] E. Cassani, G. Privitera, G. Pezzoli et al., "Use of probiotics for the treatment of constipation in Parkinson's disease patients," Minerva Gastroenterologica e Dietologica, vol. 57, no. 2, pp. 117121, 2011.

[157] D. Pohl, R. Tutuian, and M. Fried, "Pharmacologic treatment of constipation: what is new?" Current Opinion in Pharmacology, vol. 8, no. 6, pp. 724-728, 2008. 
[158] A. R. South, S. M. Somers, and M. S. Jog, "Gum chewing improves swallow frequency and latency in Parkinson patients: a preliminary study," Neurology, vol. 74, no. 15, pp. 1198-1202, 2010.

[159] R. Speyer, L. Baijens, M. Heijnen, and I. Zwijnenberg, "Effects of therapy in oropharyngeal dysphagia by speech and language therapists: A systematic review," Dysphagia, vol. 25, no. 1, pp. 40-65, 2010.

[160] L. Marks, K. Turner, J. O'Sullivan, B. Deighton, and A. Lees, "Drooling in Parkinson's disease: a novel speech and language therapy intervention," International Journal of Language and Communication Disorders, vol. 36, pp. 282-287, 2001.

[161] S. Sockalingam, C. Shammi, and G. Remington, "Clozapineinduced hypersalivation: a review of treatment strategies," Canadian Journal of Psychiatry, vol. 52, no. 6, pp. 377-384, 2007.

[162] E. Chatelut, Y. Rispail, M. Berlan, and J. L. Montastruc, "Yohimbine increases human salivary secretion," British Journal of Clinical Pharmacology, vol. 28, no. 3, pp. 366-368, 1989.

[163] G. Egevad, V. Y. A. Petkova, and O. J. A. Vilholm, "Sialorrhea in patients with Parkinson's disease: safety and administration of botulinum neurotoxin," Journal of Parkinson's disease, vol. 4, no. 3, pp. 321-326, 2014.

[164] W. H. Jost, “Treatment of drooling in Parkinson's disease with botulinum toxin," Movement Disorders, vol. 14, no. 6, p. 1057, 1999.

[165] P. K. Pal, D. B. Calne, S. Calne, and J. K. C. Tsui, "Botulinum toxin A as treatment for drooling saliva in PD," Neurology, vol. 54, no. 1, pp. 244-247, 2000.

[166] G. Lagalla, M. Millevolte, M. Capecci, L. Provinciali, and M. G. Ceravolo, "Botulinum toxin type A for drooling in Parkinson's disease: a double-blind, randomized, placebo-controlled study," Movement Disorders, vol. 21, no. 5, pp. 704-707, 2006.

[167] G. Lagalla, M. Millevolte, M. Capecci, L. Provinciali, and M. G. Ceravolo, "Long-lasting benefits of botulinum toxin type B in Parkinson's disease-related drooling," Journal of Neurology, vol. 256, no. 4, pp. 563-567, 2009.

[168] F. Mancini, R. R. Zangaglia, S. Cristina et al., "Double-blind, placebo-controlled study to evaluate the efficacy and safety of botulinum toxin type A in the treatment of drooling Parkinsonism," Movement Disorders, vol. 18, no. 6, pp. 685-688, 2003.

[169] A. Lipp, T. Trottenberg, T. Schink, A. Kupsch, and G. Arnold, "A randomized trial of botulinum toxin A for treatment of drooling," Neurology, vol. 61, no. 9, pp. 1279-1281, 2003.

[170] H. C. Hyson, A. M. Johnson, and M. S. Jog, "Sublingual atropine for sialorrhea secondary to parkinsonism: a pilot study," Movement Disorders, vol. 17, no. 6, pp. 1318-1320, 2002.

[171] M. E. L. Arbouw, K. L. L. Movig, M. Koopmann et al., "Glycopyrrolate for sialorrhea in Parkinson disease: a randomized, double-blind, crossover trial," Neurology, vol. 74, no. 15, pp. 1203-1207, 2010.

[172] P. A. Blasco and J. C. K. Stansbury, "Glycopyrrolate treatment of chronic drooling," Archives of Pediatrics and Adolescent Medicine, vol. 150, no. 9, pp. 932-935, 1996.

[173] S. J. Bachrach, R. S. Walter, and K. Trzcinski, "Use of glycopyrrolate and other anticholinergic medications for sialorrhea in children with cerebral palsy," Clinical Pediatrics, vol. 37, no. 8, pp. 485-490, 1998.

[174] R. J. Mier, S. J. Bachrach, R. C. Lakin, T. Barker, J. Childs, and M. Moran, "Treatment of sialorrhea with glycopyrrolate: a doubleblind, dose-ranging study," Archives of Pediatrics and Adolescent Medicine, vol. 154, no. 12, pp. 1214-1218, 2000.
[175] L. S. Eiland, "Glycopyrrolate for chronic drooling in children," Clinical Therapeutics, vol. 34, no. 4, pp. 735-742, 2012.

[176] D. W. Lewis, C. Fontana, L. K. Mehallick, and Y. Everett, "Transdermal scopolamine for reduction of drooling in developmentally delayed children," Developmental Medicine and Child Neurology, vol. 36, no. 6, pp. 484-486, 1994.

[177] J. A. Camp-Bruno, B. G. Winsberg, A. R. Green-Parsons, and J. P. Abrams, "Efficacy of benztropine therapy for drooling," Developmental Medicine and Child Neurology, vol. 31, no. 3, pp. 309-319, 1989.

[178] T. R. Thomsen, W. R. Galpern, A. Asante, T. Arenovich, and S. H. Fox, "Ipratropium bromide spray as treatment for sialorrhea in Parkinson's disease," Movement Disorders, vol. 22, no. 15, pp. 2268-2273, 2007.

[179] P. H. Jongerius, P. Van Tiel, J. Van Limbeek, F. J. M. Gabreëls, and J. J. Rotteveel, "A systematic review for evidence of efficacy of anticholinergic drugs to treat drooling," Archives of Disease in Childhood, vol. 88, no. 10, pp. 911-914, 2003.

[180] M. Serrano-Dueñas, “Treatment of sialorrhea in Parkinson's disease patients with clonidine. Double-blind, comparative study with placebo," Neurologia, vol. 18, no. 1, pp. 2-6, 2003.

[181] M. Kushnir, A. Eliam, and E. Heldman, "Modafinil reduces drooling in Parkinson's disease," Movement Disorders, vol. 21, supplement 15, pp. S598-S599, 2006.

[182] S. P. Lloret, G. Nano, A. Carrosella, E. Gamzu, and M. Merello, "A double-blind, placebo-controlled, randomized, crossover pilot study of the safety and efficacy of multiple doses of intraoral tropicamide films for the short-term relief of sialorrhea symptoms in Parkinson's disease patients," Journal of the Neurological Sciences, vol. 310, no. 1-2, pp. 248-250, 2011.

[183] A.-G. Postma, M. A. A. M. Heesters, and T. van Laar, "Radiotherapy to the salivary glands as treatment of sialorrhea in patients with parkinsonism," Movement Disorders, vol. 22, no. 16, pp. 2430-2435, 2007.

[184] P. M. Andersen, H. Grönberg, L. Franzen, and U. Funegård, "External radiation of the parotid glands significantly reduces drooling in patients with motor neurone disease with bulbar paresis," Journal of the Neurological Sciences, vol. 191, no. 1-2, pp. 111-114, 2001.

[185] Y. Stern, R. Feinmesser, M. Collins, S. R. Shott, and R. T. Cotton, "Bilateral submandibular gland excision with parotid duct ligation for treatment of sialorrhea in children: long-term results," Archives of Otolaryngology-Head and Neck Surgery, vol. 128, no. 7, pp. 801-803, 2002.

[186] M. De, R. Adair, K. Golchin, and M. J. Cinnamond, "Outcomes of submandibular duct relocation: a 15-year experience," The Journal of Laryngology \& Otology, vol. 117, no. 10, pp. 821-823, 2003.

[187] A. Panarese, S. Ghosh, D. Hodgson, J. McEwan, and P. D. Bull, "Outcomes of submandibular duct re-implantation for sialorrhoea," Clinical Otolaryngology and Allied Sciences, vol. 26, no. 2, pp. 143-146, 2001.

[188] W. M. Mullins, C. W. Gross, and J. M. Moore, "Long-term follow-up of tympanic neurectomy for sialorrhea," Laryngoscope, vol. 89, no. 8, pp. 1219-1223, 1979.

[189] R. W. Pelham, L. C. Nix, R. E. Chavira, M. V. Cleveland, and P. Stetson, "Clinical trial: single- and multiple-dose pharmacokinetics of polyethylene glycol (PEG-3350) in healthy young and elderly subjects," Alimentary Pharmacology and Therapeutics, vol. 28, no. 2, pp. 256-265, 2008.

[190] F. A. Lederle, D. L. Busch, K. M. Mattox, M. J. West, and D. M. Aske, "Cost-effective treatment of constipation in the 
elderly: a randomized double-blind comparison of sorbitol and lactulose," The American Journal of Medicine, vol. 89, no. 5, pp. 597-601, 1990.

[191] M. D. Kraft, I. F. Btaiche, G. S. Sacks, and K. A. Kudsk, “Treatment of electrolyte disorders in adult patients in the intensive care unit," American Journal of Health-System Pharmacy, vol. 62, no. 16, pp. 1663-1682, 2005.

[192] A. J. Singer, E. Sauris, and A. W. Viccellio, "Ceruminolytic effects of docusate sodium: a randomized, controlled trial," Annals of Emergency Medicine, vol. 36, no. 3, pp. 228-232, 2000.

[193] M. Vazquez Roque and M. Camilleri, "Linaclotide, a synthetic guanylate cyclase $\mathrm{C}$ agonist, for the treatment of functional gastrointestinal disorders associated with constipation," Expert Review of Gastroenterology and Hepatology, vol. 5, no. 3, pp. 301310, 2011.

[194] F. Durif, B. Debilly, M. Galitzky et al., "Clozapine improves dyskinesias in Parkinson disease: a double-blind, placebo-controlled study," Neurology, vol. 62, no. 3, pp. 381-388, 2004.

[195] M. W. Nelson, R. R. Reynolds, D. L. Kelly, and R. R. Conley, "Adjunctive quetiapine decreases symptoms of tardive dyskinesia in a patient taking risperidone," Clinical Neuropharmacology, vol. 26, no. 6, pp. 297-298, 2003.

[196] B. Drolet, G. Rousseau, P. Daleau, R. Cardinal, and J. Turgeon, "Domperidone should not be considered a no-risk alternative to cisapride in the treatment of gastrointestinal motility disorders," Circulation, vol. 102, no. 16, pp. 1883-1885, 2000.

[197] M. Camilleri, H. P. Parkman, M. A. Shafi, T. L. Abell, and L. Gerson, "Clinical guideline: management of gastroparesis," The American Journal of Gastroenterology, vol. 108, no. 1, pp. 18-38, 2013.

[198] R. A. Hauser, S. Isaacson, T. Clinch et al., "Randomized, placebo-controlled trial of trimethobenzamide to control nausea and vomiting during initiation and continued treatment with subcutaneous apomorphine injection," Parkinsonism and Related Disorders, vol. 20, no. 11, pp. 1171-1176, 2014.

[199] I. Soykan, I. Sarosiek, J. Shifflett, G. F. Wooten, and R. W. McCallum, "Effect of chronic oral domperidone therapy on gastrointestinal symptoms and gastric emptying in patients with Parkinson's disease," Movement Disorders, vol. 12, no. 6, pp. 952957, 1997.

[200] R. Djaldetti, M. Koren, I. Ziv, A. Achiron, and E. Melamed, "Effect of Cisapride on response fluctuations in Parkinson's disease," Movement Disorders, vol. 10, no. 1, pp. 81-84, 1995.

[201] H. Asai, F. Udaka, M. Hirano et al., "Increased gastric motility during 5-HT4 agonist therapy reduces response fluctuations in Parkinson's disease," Parkinsonism and Related Disorders, vol. 11, no. 8, pp. 499-502, 2005.

[202] L. Dézsi and L. Vécsei, "Clinical implications of irregular ADMET properties with levodopa and other antiparkinson's drugs," Expert Opinion on Drug Metabolism and Toxicology, vol. 10, no. 3, pp. 409-424, 2014.

[203] G. C. Inglis and C. J. Kenyon, "Effects of long-term infusions of dopa and carbidopa on renin and steroid secretion in the rat," Endocrinology, vol. 131, no. 6, pp. 2941-2945, 1992.

[204] D. Devos, T. Lebouvier, B. Lardeux et al., "Colonic inflammation in Parkinson's disease," Neurobiology of Disease, vol. 50, pp. 4248, 2013.

[205] C. B. Forsyth, K. M. Shannon, J. H. Kordower et al., "Increased intestinal permeability correlates with sigmoid mucosa alphasynuclein staining and endotoxin exposure markers in early Parkinson's disease," PLoS ONE, vol. 6, no. 12, Article ID e28032, 2011.
[206] V. Grozdanov, C. Bliederhaeuser, W. P. Ruf et al., "Inflammatory dysregulation of blood monocytes in Parkinson's disease patients," Acta Neuropathologica, vol. 128, no. 5, pp. 651-663, 2014.

[207] A. Keshavarzian, S. J. Green, P. A. Engen et al., "Colonic bacterial composition in Parkinson's disease," Movement Disorders, vol. 30, no. 10, pp. 1351-1360, 2015.

[208] F. Scheperjans, V. Aho, P. A. B. Pereira et al., "Gut microbiota are related to Parkinson's disease and clinical phenotype," Movement Disorders, vol. 30, no. 3, pp. 350-358, 2015.

[209] I. Celardo, L. M. Martins, and S. Gandhi, "Unravelling mitochondrial pathways to Parkinson's disease," British Journal of Pharmacology, vol. 171, no. 8, pp. 1943-1957, 2014.

[210] D. T. Dextera and P. Jenner, "Parkinson disease: from pathology to molecular disease mechanisms," Free Radical Biology and Medicine, vol. 62, pp. 132-144, 2013.

[211] C. Guardia-Laguarta, E. Area-Gomez, E. A. Schon, and S. Przedborski, "A new role for $\alpha$-synuclein in Parkinson's disease: alteration of ER-mitochondrial communication," Movement Disorders, vol. 30, no. 8, pp. 1026-1033, 2015.

[212] D. Ivankovic, K.-Y. Chau, A. H. V. Schapira, and M. E. Gegg, "Mitochondrial and lysosomal biogenesis are activated following PINK1/parkin-mediated mitophagy," Journal of Neurochemistry, vol. 136, no. 2, pp. 388-402, 2016.

[213] E. D. Plowey, S. J. Cherra III, Y.-J. Liu, and C. T. Chu, "Role of autophagy in G2019S-LRRK2-associated neurite shortening in differentiated SH-SY5Y cells," Journal of Neurochemistry, vol. 105, no. 3, pp. 1048-1056, 2008.

[214] R. C. S. Seet, C.-Y. J. Lee, E. C. H. Lim et al., “Oxidative damage in Parkinson disease: measurement using accurate biomarkers," Free Radical Biology and Medicine, vol. 48, no. 4, pp. 560-566, 2010.

[215] W. W. Smith, H. Jiang, Z. Pei et al., "Endoplasmic reticulum stress and mitochondrial cell death pathways mediate A53T mutant alpha-synuclein-induced toxicity," Human Molecular Genetics, vol. 14, no. 24, pp. 3801-3811, 2005. 


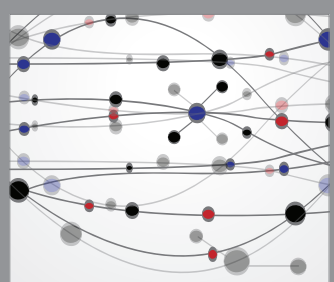

The Scientific World Journal
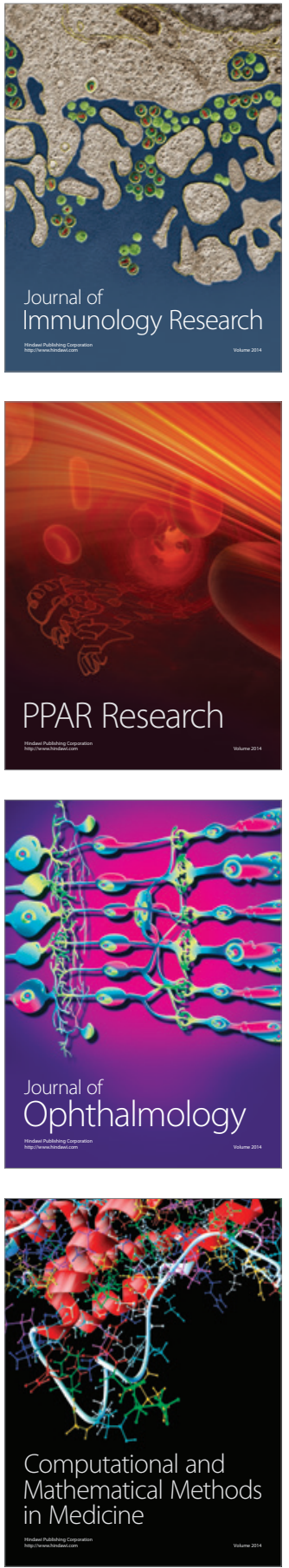

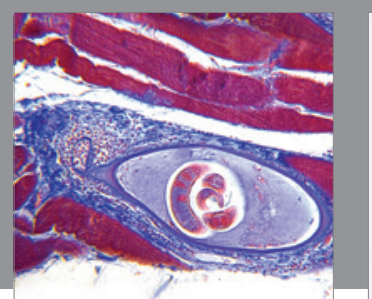

Gastroenterology Research and Practice

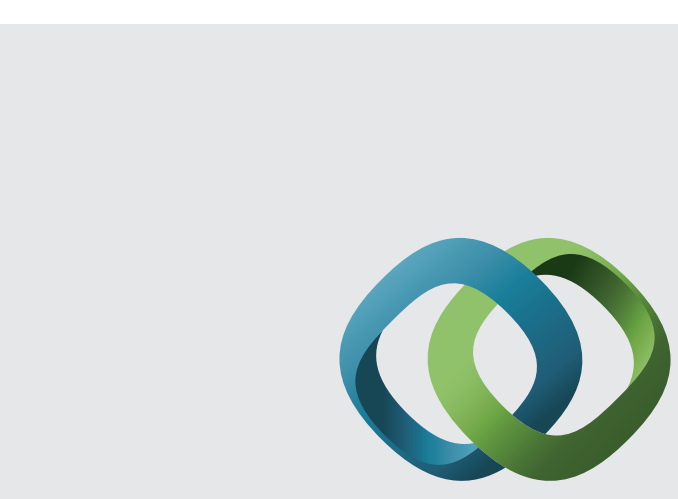

\section{Hindawi}

Submit your manuscripts at

http://www.hindawi.com
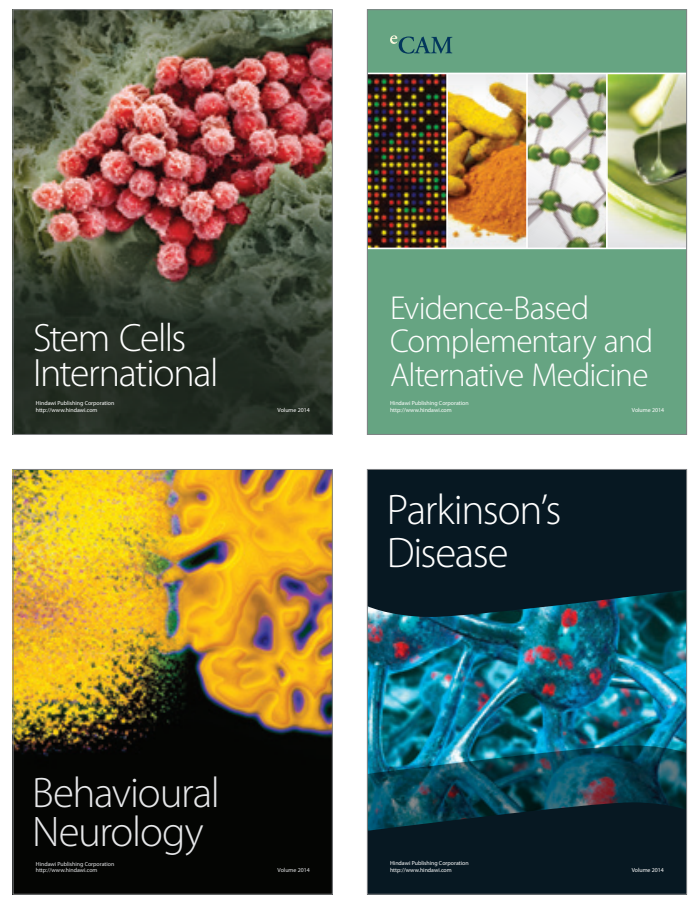
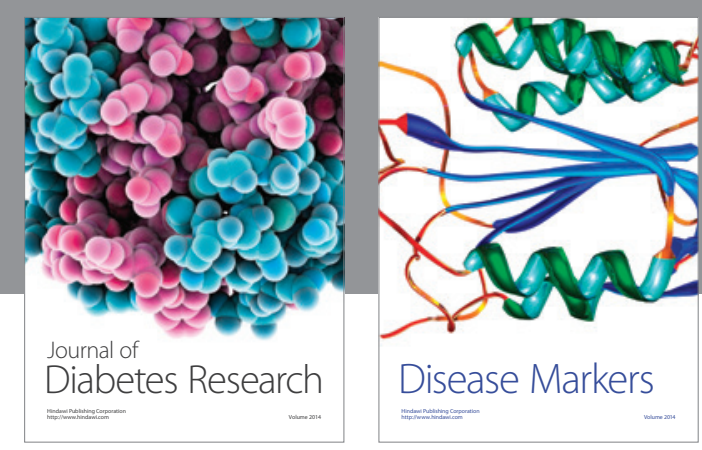

Disease Markers
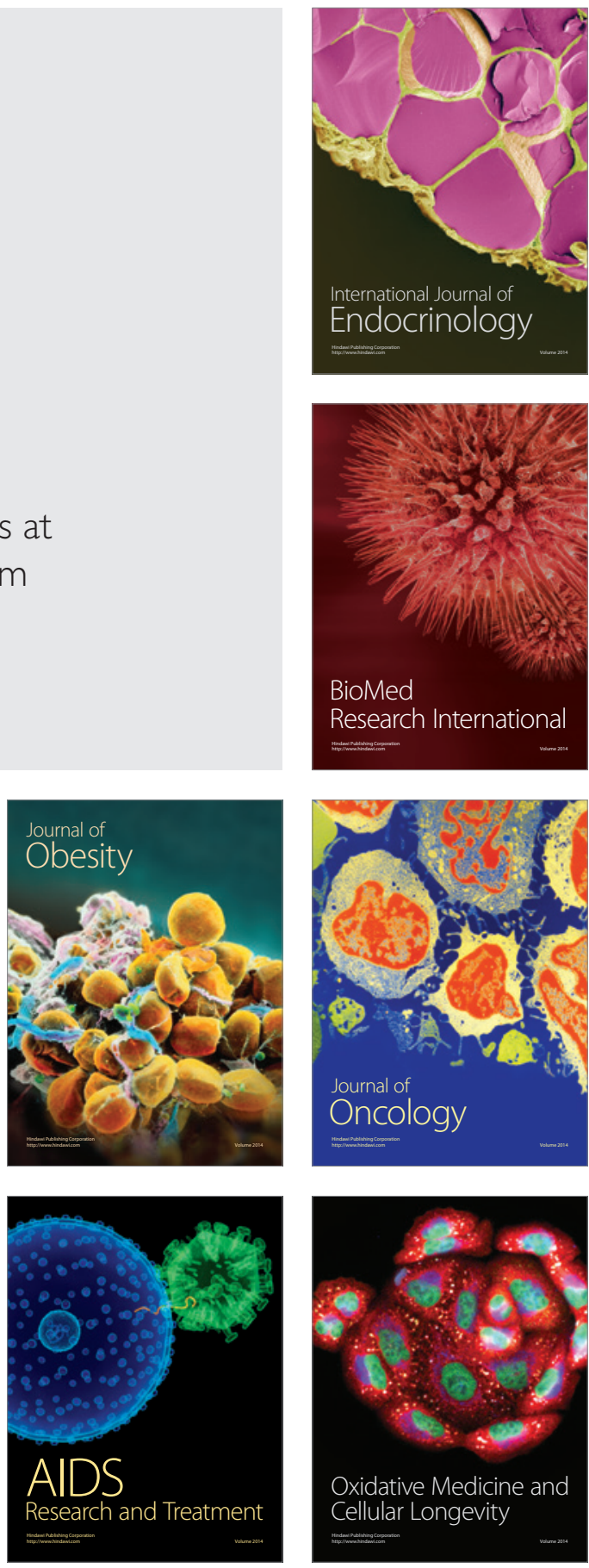